\title{
Flaviviruses: Yellow Fever, Japanese B, West Nile, and Others
}

\author{
Stephen J. Thomas, Luis J. Martinez, and Timothy P. Endy
}

\section{Introduction}

Historically and currently the flaviviruses are important human pathogens both as endemic viruses restricted to specific geographic areas and as emerging pathogens. Yellow fever, West Nile virus, and the dengue viruses (not discussed in this chapter) represent previous, current, and future important emerging pathogens that have produced large epidemics and human deaths. Why are these viruses such a threat to human populations as emerging pathogens? Several important factors interplay to create these pathogens as agents of emerging diseases. As mostly arthropod-borne viruses (arboviruses), they have complex life cycles involving both arthropods and vertebrate hosts with a life cycle involving all life stages of the arthropods (mosquitoes, ticks, and midges) and their reservoirs of vertebrates (birds or rodents) and ultimately higher vertebrates (humans) through the bite of the infected arthropod vector. The flaviviruses all contain ribonucleic acid (RNA) as their genetic core and as such have a high rate of mutations and thus adapt quickly to changes in vector competence and the environment. Climate change, urbanization, and increasing ease of travel have created opportunities for the vector to spread and expand into human populations. The combination of these factors produces a family of viruses that can change and emerge quickly as important human pathogens.

S.J. Thomas, MD • L.J. Martinez, MD

Viral Diseases Branch,

Walter Reed Army Institute of Research,

503 Robert Grant Ave, Silver Spring, MD 20910-7500, USA

e-mail: stephen.j.thomas3.mil@mail.mil;

luis.j.martinez@us.army.mil

T.P. Endy, MD, MPH $(\bowtie)$

Infectious Disease Division, Department of Medicine,

State University of New York, Upstate Medical University,

725 Irving Avenue, E. Adams St., CPOB Suite 304,

Syracuse, NY 13210, USA

e-mail: endyt@upstate.edu
Yellow fever virus (discussed in detail in this chapter) was the first arbovirus identified in the 1800s as responsible for large epidemics of hemorrhagic fever in Africa and North, Central, and South America. By 1960 scientists recognized serologically two distinct arboviruses: the group A arboviruses now known as the family Togaviridae and the group B arboviruses, renamed the family Flaviviridae [1]. Serologic comparisons among the flaviviruses revealed cross-reactivity within groups distinguishing the flaviviruses as mosquito borne, tick borne, or nonvectored [2]. According to the International Committee on Taxonomy of Viruses, a subgroup of the Division of Virology of the International Union of Microbiology Societies, the Family Flaviviridae is comprised of three genera: Flavivirus, Hepacivirus, and Pestivirus (http://ictvonline.org/index.asp). Information on their isolation, morphology, sensitivity to inactivation by chemicals, arthropod vectors, vertebrate hosts, laboratory propagation, serologic reactions, geographic distribution, clinical manifestations, and epidemiology is found in the International Catalogue of Arthropod-Borne Viruses, compiled by the American Committee on Arthropod-Borne Viruses (ACAV) [3]. This exhaustive reference source has been used freely in preparing the text that follows. Hepacivirus and Pestivirus are discussed elsewhere in this textbook, and the focus of this chapter will be on the pathogenic viruses within the genera Flavivirus. The dengue viruses are discussed in a separate chapter. Within the genus Flavivirus there are 53 species of viruses and displayed in Table 16.1.

Despite their species variation, the flaviviruses have a remarkable genetic conservation throughout its genus [4]. The genome is a single positive-stranded RNA, 11 kilobases in length, encoding the viral proteins from an open reading frame (ORF) of over 10,000 bases of approximately 3,434 amino acids [4]. The proteins encoded from the ORF is $5^{\prime}-\mathrm{C}$ prM (M)-E-NS I-NS2A-NS2B-NS3-NS4A-NS4B-NS5-3'. The structural proteins $\mathrm{C}$ (capsid), $\mathrm{M}$ (membrane), and $\mathrm{E}$ (envelope) comprise the outer coat of the flaviviruses and the epitopes responsible for attachment to host cells and cell entry. The nonstructural proteins include the highly 
Table 16.1 Taxonomy of viruses of the family Flaviviridae, genera Flavivirus

\begin{tabular}{|c|c|c|c|c|}
\hline Group (by vector) & Abbreviation & Geographic distribution & Principal vector species & Human disease \\
\hline \multicolumn{5}{|l|}{ Tick-borne viruses } \\
\hline \multicolumn{5}{|l|}{ Mammalian tick-borne virus complex } \\
\hline Alkhurma hemorrhagic fever virus & AHFV & Egypt, Sudan & Camel tick & Hemorrhagic fever \\
\hline Gadgets Gully virus & GGYV & Australia & Ixodes uriae & Unknown \\
\hline Kadam virus & KADV & Uganda, Saudi Arabia & Rhipicephalus pravus & Unknown \\
\hline Kyasanur Forest disease virus & KFDV & India, China & Haemaphysalis spinigera & Hemorrhagic fever \\
\hline Langat virus & LGTV & Malaysia, Thailand, Siberia & Ixodes granulatus & Fever \\
\hline Omsk hemorrhagic fever virus & OHFV & Russia and Central Asia & Dermacentor pictus & Hemorrhagic Fever \\
\hline Powassan virus & POWV & Canada and Northern United States & Ixodes spp. & Encephalitis \\
\hline Royal Farm virus & RFV & Afghanistan & Argas spp. & Unknown \\
\hline Karshi virus & KSIV & Central Asia & Ornithodoros papillipes & Encephalitis \\
\hline Tick-borne encephalitis virus & TBEV & Europe, Asia & Ixodes spp. & Encephalitis \\
\hline European subtype & & Europe, Asia & Ixodes spp. & Encephalitis \\
\hline \multicolumn{5}{|l|}{ Far Eastern subtype } \\
\hline \multicolumn{5}{|l|}{ Siberian subtype } \\
\hline Louping ill virus & LIV & United Kingdom & Ixodes spp. & Encephalitis \\
\hline Irish subtype & & Ireland & Ixodes spp. & Encephalitis \\
\hline British subtype & & United Kingdom & Ixodes spp. & Encephalitis \\
\hline Spanish subtype & & Spain & Ixodes spp. & Encephalitis \\
\hline Turkish subtype & & Turkey & Ixodes spp. & Encephalitis \\
\hline \multicolumn{5}{|l|}{ Mosquito-borne viruses } \\
\hline \multicolumn{5}{|l|}{ Aroa virus complex } \\
\hline Aroa virus & AROAV & Venezuela & Unknown & Unknown \\
\hline Bussuquara virus & BSQV & Brazil, Colombia, Panama & Culex spp. & Fever \\
\hline Iguape virus & IGUV & Brazil & Unknown & Unknown \\
\hline Naranjal virus & NJLV & Ecuador & Culex spp. & Unknown \\
\hline
\end{tabular}

Dengue virus complex

Dengue virus

Dengue virus type

DENV-1

DENV-2

Tropical and subtropical regions of the world for all

Aedes aegypti for all

DENV-3

Dengue virus type 3

Dengue virus type 4

DENV-4

Kedougou virus

Japanese encephalitis virus complex

Cacipacore virus

Koutango virus

Japanese encephalitis virus

Murray Valley encephalitis virus

Alfuy virus

St. Louis encephalitis virus

Usutu virus

West Nile virus

Kunjin virus

Yaounde virus

Kokobera virus complex

Kokobera virus

Stratford virus

Ntaya virus complex

Bagaza virus

Ilheus virus

Rocio virus

Israel turkey meningoencephalitis virus

Ntaya virus

\begin{tabular}{|c|c|c|c|}
\hline KEDV & Senegal, Central Africa & Aedes spp. & Unknown \\
\hline $\mathrm{CPCV}$ & Brazil & Unknown & Unknown \\
\hline KOUV & Senegal, Central Africa & Aedes spp. & Unknown \\
\hline JEV & Asia & Culex spp. & Encephalitis \\
\hline MVEV & Australia & Culex annulirostris & Encephalitis \\
\hline ALFV & Australia & Unknown & Unknown \\
\hline SLEV & North, Central, and South America & Culex spp. & Encephalitis \\
\hline USUV & Africa & Mosquitoes & Fever, rash \\
\hline WNV & Worldwide & Culex spp. & Encephalitis \\
\hline KUNV & Australia, Asia & Culex spp. & Fever, rash \\
\hline YAOV & Cameroon & Culex spp. & Unknown \\
\hline KOKV & Australia & Culex annulirostris & Unknown \\
\hline STRV & Australia & Aedes vigilax & Unknown \\
\hline BAGV & Africa & Culex spp. & Fever \\
\hline ILHV & Central and South America & Mosquitoes & Fever \\
\hline ROCV & Brazil & Mosquitoes & Encephalitis \\
\hline ITV & Israel & Unknown & Unknown \\
\hline NTAV & Africa & Mosquitoes & Fever \\
\hline
\end{tabular}

Fever, Hemorrhagic fever, encephalitis 
Table 16.1 (continued)

\begin{tabular}{|c|c|c|c|c|}
\hline Group (by vector) & Abbreviation & Geographic distribution & Principal vector species & Human disease \\
\hline Tembusu virus & TMUV & Malaysia, Thailand & Culex spp. & Unknown \\
\hline \multicolumn{5}{|l|}{ Spondweni virus complex } \\
\hline Zika virus & ZIKV & Africa, Asia & Aedes spp. & Fever, rash \\
\hline Spondweni virus & SPOV & Africa & Aedes circumluteolus & Unknown \\
\hline \multicolumn{5}{|l|}{ Yellow fever virus complex } \\
\hline Banzi virus & BANV & Africa & Culex spp. & Fever \\
\hline Bouboui virus & BOUV & Africa & Unknown & Unknown \\
\hline Edge Hill virus & EHV & Australia & Mosquitoes & Unknown \\
\hline Jugra virus & JUGV & Malaysia & Mosquitoes & Unknown \\
\hline Saboya virus & SABV & Senegal & Tatera kempi & Unknown \\
\hline Potiskum virus & POTV & Nigeria & Unknown & Unknown \\
\hline Sepik virus & SEPV & New Guinea & Mosquitoes & Fever \\
\hline Uganda $S$ virus & UGSV & Africa & Mosquitoes & Unknown \\
\hline Wesselsbron virus & WESSV & Africa, Asia & Aedes spp. & Fever \\
\hline Yellow fever virus & YFV & Africa, South America & Aedes aegypti & Hemorrhagic fever \\
\hline \multicolumn{5}{|c|}{ Viruses with no known arthropod vector } \\
\hline \multicolumn{5}{|l|}{ Entebbe bat virus complex } \\
\hline Entebbe bat virus & ENTV & Uganda & Unknown & Unknown \\
\hline Sokoluk virus & SOKV & Kyrgyzstan & Unknown & Unknown \\
\hline Yokose virus & YOKV & Japan & Unknown & Unknown \\
\hline \multicolumn{5}{|l|}{ Modoc virus complex } \\
\hline Apoi virus & APOIV & Japan & Unknown & Unknown \\
\hline Cowbone Ridge virus & CRV & USA & Unknown & Unknown \\
\hline Jutiapa virus & JUTV & Guatemala & Unknown & Unknown \\
\hline Modoc virus & MODV & USA & Unknown & Unknown \\
\hline Sal Vieja virus & SVV & USA & Unknown & Unknown \\
\hline San Perlita virus & SPV & USA & Unknown & Unknown \\
\hline \multicolumn{5}{|l|}{ Rio Bravo virus complex } \\
\hline Bukalasa bat virus & BBV & Uganda & Unknown & Unknown \\
\hline Carey Island virus & CIV & Malaysia & Unknown & Unknown \\
\hline Dakar bat virus & DBV & Africa & Unknown & Fever \\
\hline Montana myotis leukoencephalitis virus & MMLV & USA & Unknown & Unknown \\
\hline Phnom Penh bat virus & PPBV & Cambodia & Unknown & Unknown \\
\hline Batu Cave virus & $\mathrm{BCV}$ & Malaysia & Unknown & Unknown \\
\hline Rio Bravo virus & RBV & USA, Mexico & Unknown & Fever \\
\hline
\end{tabular}

Adapted from Calisher et al. [1]

conserved proteins NS1, NS3, and NS5 and the four small hydrophobic proteins NS2A, NS2B, NS4A, and NS4B [4].

Molecular and phylogenetic analysis of the genus Flavivirus reveals a family of viruses that has evolved rapidly from a progenitor virus arising possibly in Africa several thousands of years ago. With evolution the flaviviruses have shown substantial ecological diversification with different lineages adapting to different vectors and modes of transmission. They have also evolved unique strategies to evade the host's innate and adaptive immunity [5]. Figure 16.1 displays the phylogenetic tree of the genus Flavivirus showing the association of the groups of related viruses with their invertebrate vectors, vertebrate hosts, and geographic distribution. All human pathogenic flaviviruses are transmitted by insect vectors, and all but the dengue viruses have an animal host (i.e., they are zoonotic). The ecological speciations of these viruses are diverse. For example, the Japanese encephalitis virus (JEV) group (e.g., Japanese encephalitis virus, West Nile virus (WNV), St. Louis encephalitis (SLE)) is maintained in a cycle of transmission between birds and Culex mosquitoes. Mammalian hosts, humans, and horses are infected but are dead-end hosts as the viremia achieved is too low for subsequent transmission to an insect vector. The tick-borne encephalitis group is transmitted among rodents by a tick vector; as with the JEV group, humans are a deadend host. Yellow fever virus (YFV) is primarily maintained in a sylvatic cycle involving nonhuman primates and Aedes mosquitoes; but it has shown the capacity to spread in urban areas using Aedes aegypti mosquitoes and humans as its primary reservoir, resulting in extensive urban epidemics. 


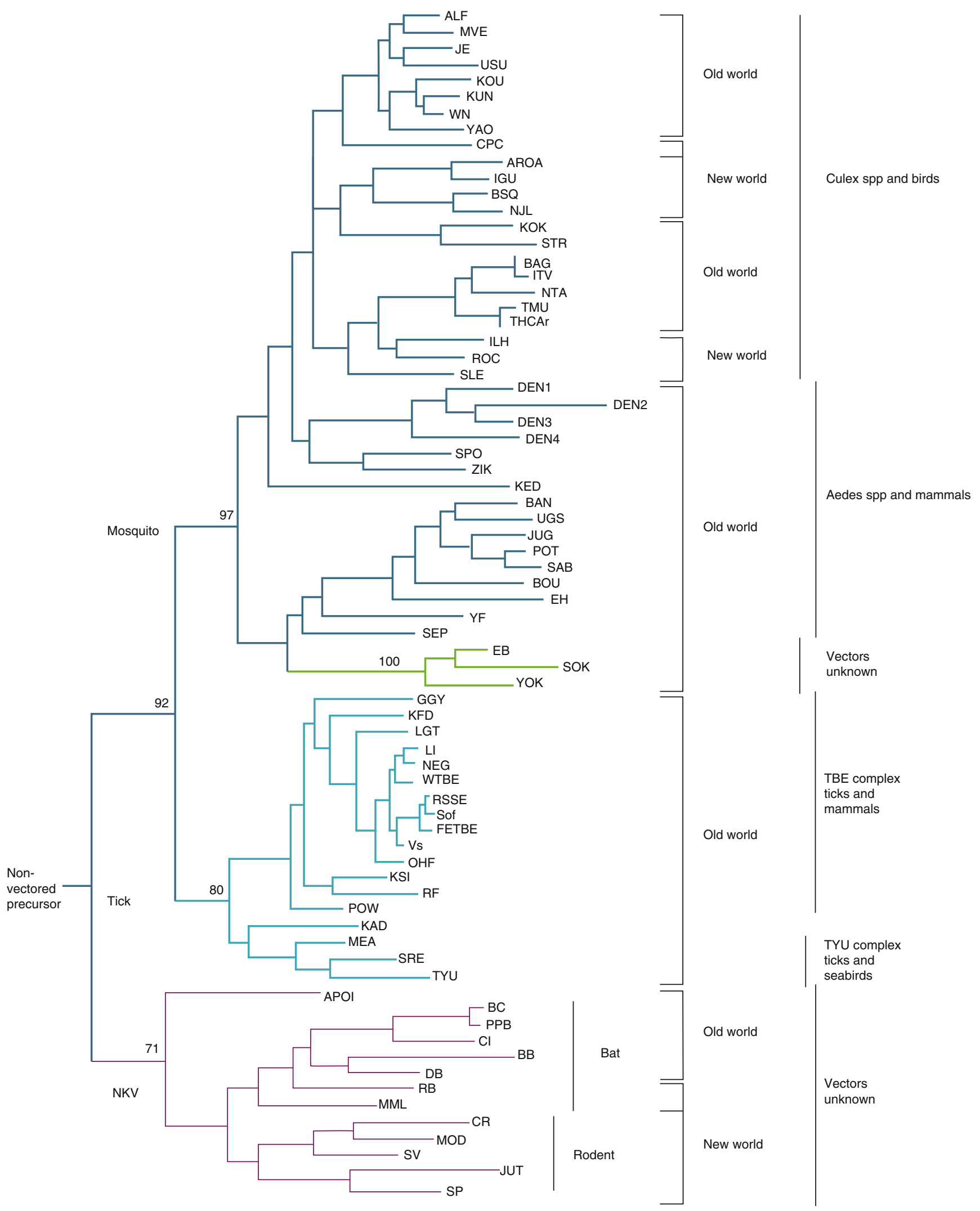


Analysis of the genetic changes of the flaviviruses over time reveals a group of viruses that have evolved rapidly. Methods using coalescent theory and a maximum likelihood (ML) demographic model reveal that the flaviviruses are growing at an exponential rate, with specific viruses such as the dengue viruses increasing rapidly in the recent past and Japanese encephalitis virus changing from constant population size to exponential growth within the last century [6]. For St. Louis encephalitis virus (SLEV), a Bayesian coalescent approach was used on the envelope gene sequence substitution rates and dates of divergence in the Americas [7]. The mean substitution rate estimated for all SLEV was $4.1 \times 10^{-4}$ substitutions/site/year. The direction of the gene flow was South to North between $158 \mathrm{~N}$ and $308 \mathrm{~N}$ latitude consistent with migratory bird patterns from their northern breeding grounds after having acquired infection while wintering in the region of the Gulf of Mexico. This is an elegant example of the role of the vector and the vertebrate host especially migratory birds in influencing the gene flow and evolution of the flaviviruses. The dengue viruses (DENVs) are also an example of an emerged flavivirus and global health problem that have changed dramatically over the past century. DENV has evolved to a molecular clock that is serotype and genotype specific [8]. Phylogenetic analysis and time analysis suggest that dengue viruses serotypes separated within the last 1,000 years, and the change of DENV from a sylvatic cycle to sustained human transmission may have occurred between 125 and 320 years ago [9].

In this chapter we will review the characteristics of the flaviviruses, their modes of transmission, and their role in causing severe human clinical infection and emerging diseases of potential epidemiologic significance.

\section{$2 \quad$ Historical Background}

Yellow fever and its emergence as a deadly epidemic disease is a model on how diseases emerge to become a large recurrent epidemic disease in urban populations. Originally an African virus unknown to the western world prior to the 1600s, was introduced to the Western Hemisphere by the transportation of slaves from Africa with the first reported outbreak of yellow fever in the Yucatan in 1648 [10]. The transportation of the mosquito vector and infected passengers by ship and introduction of the virus into naive susceptible populations resulted over the next 200 years in the transmission of the virus and illness to many large urban populations with outbreaks occurring in the tropical Americas, costal North America, and Europe. Yellow fever became known in the Hispanic world as La Vomito for the black vomit that accompanies the hemorrhagic phase and yellow jack among the Europeans for the international signal flag for quarantine and its characteristic yellow and black squares known by the same name. During the summer months, epidemics occurred in New York in 1668, Boston in 1691, and Charleston in 1699, as well as later in the cities of the Gulf of Mexico and the Mississippi River. In 1793 a major yellow fever epidemic occurred in Philadelphia. Philadelphia at that time was the United States' largest and most cosmopolitan city. French refugees from a slave rebellion in Haiti arrived on the banks of the Delaware River which bounds the east side of the city bringing yellow fever with them [11]. In July of that year, cases developed among the working class living along the Delaware River who suffered high fevers, yellowing of the skin and eyes, hemorrhage, and death. By August 19 the epidemic potential was recognized by Dr. Benjamin Rush, professor at the University of Pennsylvania, founder of the College of Physicians of Philadelphia, and signer of the Declaration of Independence. Dr. Rush later gave an accounting of his clinical experience during this epidemic in a publication entitled, "An Account of the Bilious Remitting Yellow Fever, as It Appeared in the City of Philadelphia, in the Year 1793." The epidemic peaked in October of that year with total deaths estimated to be 4,041-5,000 in a population of 45,000 (crude mortality of 9-11\%). Subsequently Philadelphia experienced outbreaks of yellow fever in 1797, 1798, 1799, 1802, 1803, and 1805.
Fig. 16.1 Phylogenetic tree showing the association of the groups of related viruses with their invertebrate vectors, vertebrate hosts, and geographic distribution. ALF Alfuy, $M V E$ Murray Valley encephalitis, $J E$ Japanese encephalitis, USU Usutu, KOU Koutango, KUN Kunjin, $W N$ West Nile, $Y A O$ Yaounde, $C P C$ Cacipacore, $A R O$ Aroa, $I G U$ Iguape, NJL Naranjal, KOK Kokobera, STR Stratford, BAG Bagaza, IT Israel Turkey meningoencephalomyelitis virus, TMU Tembusu, THCAr strain of Tembusu, ILH Ilheus, ROC Rocio, SLE St. Louis encephalitis, DEN dengue, SPO Spondweni, ZIK Zika forest, KED Kedougou, UGS Uganda S, JUG Jugra, POT Potiskum, $S A B$ Saboya, BOU Bouboui, EH Edge Hill, $Y F$ yellow fever, $S E P$ Sepik, $E B$ Entebbe bat, $S O K$ Sokoluk, $Y O K$ Yokose, $G G Y$ Gadgets Gully, KFD Kyasanur Forest disease, $L G T$
Langat, LI Louping ill, NEG Negishi, Sof Sofjin, FETBE far eastern TBE, $V s$ Vasilchenko, OHF Omsk haemorrhage fever, $K S I$ Karshi, $R F$ Royal Farm, POW Powassan, KAD Kadam, MEA Meaban, SRE Saumarez Reef, TYLI Tyuleniy, APOI Apoi, $B C$ Batu Cave, $P P B$ Phnom Penh bat, $C I$ Carey Island, $B B$ Bukalasa bat, $D B$ Dakar bat, $R B$ Rio Bravo, $M M L$ Montana myotis leucoencephalitis, $C R$ Cowbone Ridge, $M O D$ Modoc, $S V$ Sal Vieja, JUT Jutiapa, $S P$ San Perlita, TBE tickborne encephalitis, WTBE Western European TBE, RSSE Russian spring and summer encephalitis, $N K V$ refers to viruses with no known vector (Adapted from Ref. [2] with permission of the publisher) Reprinted with permission from [296] 
Yellow fever took its toll on deployed US soldiers in the tropical Americas, especially in Cuba. Army Surgeon-General George Miller Sternberg created the US Army Yellow Fever Commission in 1893 and directed Major Walter Reed to conduct studies to establish its etiology. Together with his colleagues and Carlos Finlay, a series of human clinical trials were performed in Havana, Cuba, during 1900-1901 to discover the cause of yellow fever. Walter Reed, Jas Carroll, and Aristides Agramonte published in the JAMA in 1901 The Etiology of Yellow Fever: An Additional Note where they discussed the methods of their studies, results, analysis, and concluded the following: (1) the mosquito serves as the intermediate host for the parasite of yellow fever; (2) yellow fever is transmitted to the nonimmune individual by means of the bite of the mosquito that has previously fed on the blood of those sick with this disease; (3) an interval of about 12 days or more after contamination appears to be necessary before the mosquito is capable of conveying the infection; (4) yellow fever is not conveyed by fomites, and hence disinfection of articles of clothing, bedding, or merchandise, supposedly contaminated by contact with the sick with this disease, is unnecessary; and (5) the spread of yellow fever can be most effectually controlled by measures directed to the destruction of mosquitoes and the protection of the sick against the bites of those Insects [12].

With this information, General William C. Gorgas engineered the elimination of the mosquito initially from Havana and then later from the environs of the Panama Canal construction site and subsequently yellow fever cases disappeared [13-16]. In 1932, Soper and colleagues showed that there was a jungle cycle of yellow fever in the absence of A. aegypti. This significant observation meant that yellow fever could not be stopped just by controlling the mosquitoes in the cities. Theiler and Smith succeeded in cultivating the Asibi strain of yellow fever virus, first in monkeys and then in embryonated eggs, and attenuated it by passage [17]. In 1937, they announced their discovery of an attenuated vaccine-the 17D strain [18]. This vaccine is used throughout the world today to prevent yellow fever.

The discovery of the role of Aedes aegypti in the transmission and spread of yellow fever introduced the concept of mosquito control as an effective measure to disrupt yellow fever transmission. The International Health Board and the Rockefeller Foundation instituted mosquito control strategies including the use of a larvicidal, Paris green, throughout the United States and Central and South America [19]. These techniques were applied to malaria control during the years from 1924 to 1925 [19]. World War II created the Rockefeller Foundation Health Commission in 1942 to support national defense and malaria control for US forces. The need for lousicides to combat typhus introduced a new insecticide developed by the Swiss firm, Geigy, called dichlorodiphenyltrichloroethane (DDT) [19]. Led by Fred Soper, the Rockefeller team demonstrated the effectiveness of DDT as a lousicides and in disrupting typhus epidemics. DDT was soon used in aerial and ground spraying for Allied Forces during a malaria outbreak in
Italy and was found to be highly effective. DDT became a key component of the World Health Organization's global malaria eradication campaign in 1955 [19]. This campaign resulted in the elimination of both the malaria mosquito vector and Aedes aegypti throughout South America and the virtual elimination of malaria, yellow fever, and dengue throughout the Americas. The growing concerns of the environmental effects of DDT led to the end of the use of DDT as an effective mosquito control larvicide in 1969 [20]. The cessation of the DDT-based mosquito control programs in the Americas and the social disruption that resulted from World War II allowed the emergence of dengue in Asia and its reintroduction and resurgence in the Americas.

By the 1950s, scientists of the Rockefeller Foundation, the US Army and Navy, the US Public Health Service, several US universities, and many foreign governments recognized that arboviruses could be recovered in nature from apparently healthy arthropods and wild vertebrate animals. This search in the natural cycles of arboviruses resulted in the discovery of over 500 different arboviruses with about 100 of them causing human disease. Unfortunately, the control of arbovirus infections has not kept pace with the discovery and spread of disease. Antiviral drugs for arboviruses are not commercially available. Except for yellow fever, tick-borne encephalitis, and Japanese encephalitis, there are no widely used vaccines available for humans. Source reduction and control measures against the mosquito vector such as pesticides and biological larvicides have neither been sustainable nor effective in vector control.

\section{Methodology Involved in Epidemiologic Analysis}

\subsection{Sources of Mortality and Morbidity Data}

Mortality data are collected systematically but passively by national governments for many arboviruses. Data are published in the Morbidity and Mortality Weekly Report of the US Centers for Disease Control and Prevention, in the Weekly Epidemiological Report of the Pan American Health Organization, and in the Weekly Epidemiological Report of the World Health Organization. The mortality data are grossly underreported but may serve as a comparative data base, since underreporting may be uniform throughout much of the world. The reporting of yellow fever mortality in Africa, for instance, was found to be about $10 \%$ of the true figure [14, 21].

The information flow to the World Health Organization is sometimes facilitated by informal networks of scientists and interested citizens. Nevertheless, the organization is constrained from action until official reports are received. This constraint often means a delay in control of a disease of regional or world importance.

The same sources supply morbidity data as supply mortality data. In the United States, of the arbovirus diseases, those 
producing neuroinvasive and non-neuroinvasive illnesses are reported and include the California serogroup virus, Eastern and Western equine encephalitis virus, and the flaviviruses Powassan virus, St. Louis encephalitis virus, and West Nile virus [22]. In addition, yellow fever is still reportable in the United States. Monath documented the time elapsed between onset of an epidemic of St. Louis encephalitis and its recognition [23]. That time varied between 2 and 8 weeks. In the Corpus Christi, Texas, epidemic of 1966, nearly 707 of the cases had occurred before recognition.

\subsection{Serologic Surveys}

Serologic surveys entail the sampling of a defined population and measuring the amount of specific antibody to the targeted protein which will indicate past or current infection. Because of the large sample size that is tested, highthroughput assays such as enzyme-linked immunosorbent assay (ELISA), complement fixation (CF), or hemagglutination inhibition (HAI or HI) are performed with confirmation by more time-intensive assays such as the plaque reduction neutralization titers (PRNT). The results give a point prevalence of past or current infection in different geographic areas and subpopulations or those at particular risk for infection. Distribution of the antibody in a population can give clues to the ecological conditions necessary for maintenance of the virus as well as the human behavior that might place persons at risk for infection. Surveys of different age groups will show if the virus is more prevalent as the population ages, typical of an endemically transmitted agent. Another prevalence pattern in which antibody is present only in persons born before a certain year may indicate an epidemic in that year. Alternatively, a constant percentage of antibodies in each age group may indicate a recent introduction of the virus in a naïve population. Broadly based serologic surveys of large populations can provide extensive information about virus distribution in different geographic areas, rural versus urban populations, different age and sex groups, and different occupational types. Arbovirus serosurveys have limitations. Cross-reactions occur among viruses of the same serogroup. This is especially true of the HI test and ELISA with flaviviruses. The neutralization test is more specific and should be used where feasible. Surveys with HI or ELISA must be interpreted with caution unless one is certain that only one flavivirus circulates in the region, or unless the results have been confirmed by neutralization test with a portion of the negative and positive sera.

The serosurvey usually will not indicate when the infection responsible for the antibody occurred. If the antibody is suspected to be of recent origin, the IgM antibody-capture ELISA is useful for detection of infections originating within the prior 3-6 months. A serosurvey is not a reliable indicator of natural infection in populations vaccinated for tick-borne encephalitis, yellow fever, or Japanese encephalitis. On the other hand, the survey is an excellent tool for determination of vaccination coverage and protection.

One very important use of serosurveys is in the calculation of the basic reproductive ratio, R naught $\left(R_{0}\right)$ [24], which is defined as the number of new individuals in a susceptible population who are infected by a single individual during his/ her infectious period (see also Chaps. 1 and 5). The higher the number, e.g., $R_{0}>1$, the more transmissible the infection. For vector-borne diseases, in particular, $R_{0}$ is important and complicated as it takes into account the susceptible and infected vectors as well as the susceptible and infected vertebrate hosts; $R_{0}$ is thereby influenced by both the intrinsic and extrinsic incubation periods. Serosurveys can calculate the $R_{0}$ as a measurement of the epidemic impact of a pathogen on a population but also as an estimate on the impact of interventions such as vector control on reducing disease in a population. Furthermore, a concept integrally related to $R_{0}$ is the "critical vaccination threshold," which is the number of persons in a population needed to vaccinate in order to drive $R_{0}$ to $<1$. Thus, determining $R_{0}$ by serosurveys is important not only in gauging the epidemic potential of a pathogen but also in determining the interventions necessary to control an epidemic. Age-stratified seroprevalence studies with cohorts including ages surrounding the age of peak incidence allows estimation of the force of infection over previous years based on different exposure rates across age groups and a calculation of $R_{0}$ [25].

\subsection{Laboratory Methods}

The laboratory is an all-important resource and key cornerstone in the study of the epidemiology of arbovirus diseases as well as understanding the pathogenesis of severe illness. Diagnosis can rarely be made with certainty by clinical examination and understanding the clinical course of symptoms, viremia, and antibody rise essential in utilizing the appropriate laboratory assays. Isolation of virus from arthropods, wild and domestic animals, and people is essential to determine the natural history of infection with these agents. Figure 16.2 demonstrates the typical flavivirus infection after inoculation from a vector assuming an incubation period of 6 days. Viremia occurs prior to the first clinical symptoms with early symptoms, commonly fever, headache, myalgias, and laboratory findings of leukopenia and thrombocytopenia. Antibody rises late in the clinical illness with first IgM followed by IgG. IgM can persist for several months and disappear, while IgG can persist for years after the infection. From a laboratory perspective the utility of the assay is dependent on the stage of infection. PCR-based assays and viral isolation are useful during the days of viremia in the early part of the clinical illness, whereas antibody-based assays are useful during the latter part of the illness and in convalescent sera.

Nonstructural protein 1 or NS1 is a highly conserved $48-\mathrm{kDa}$ glycoprotein that is a requirement for flavivirus 


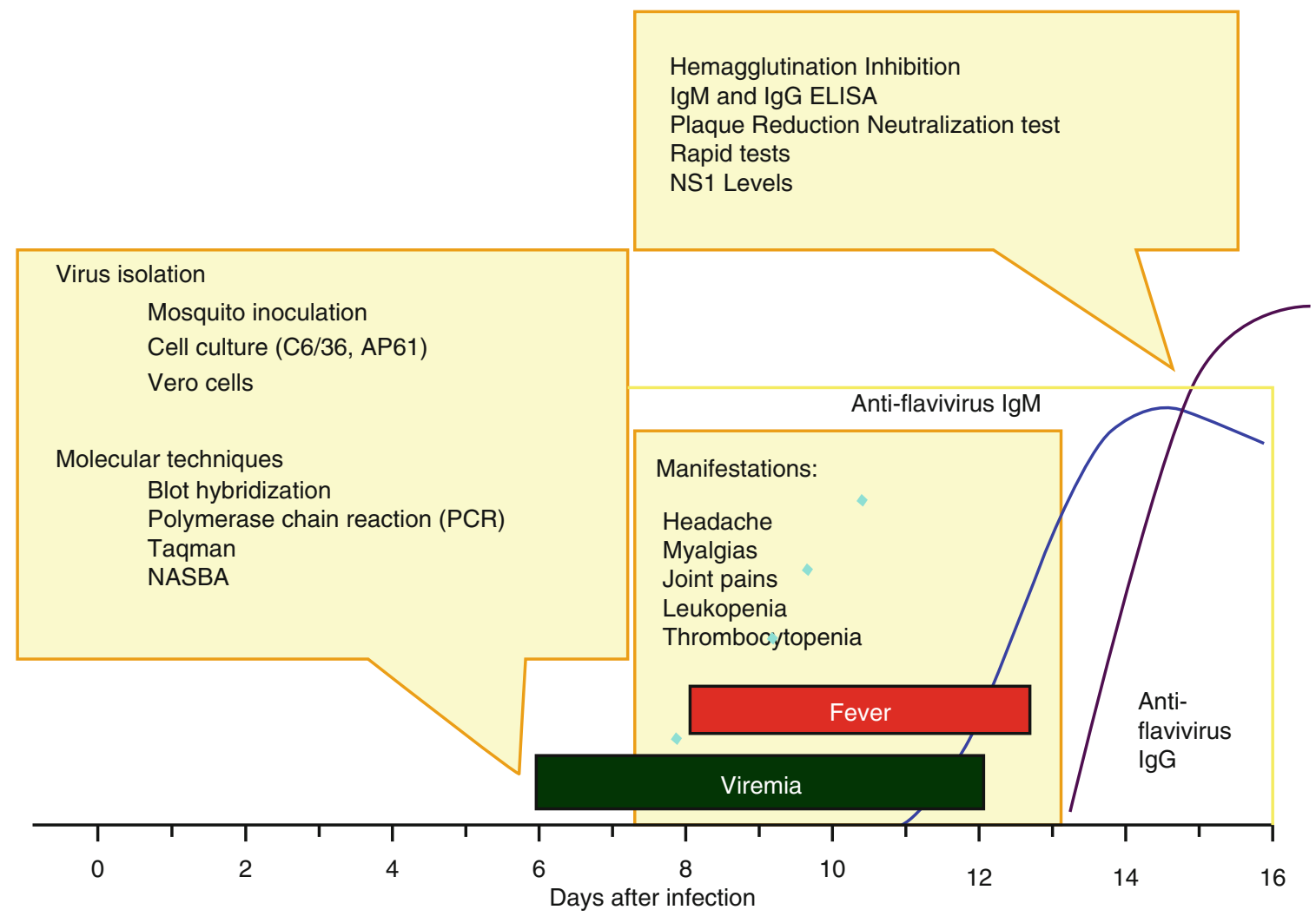

Fig. 16.2 Typical flavivirus infection and the human host response by clinical course and appropriate diagnostic assay

RNA replication [26]. Interestingly NS1 exists in the cell as a homodimer associated with organelle membranes and is actively transported to the mammalian cell surface where it is secreted as a soluble hexamer. Thus, NS1 can be detected in serum during flavivirus infections and has a half-life longer than detectable RNA in serum [27]. NS1 ELISA-based assays have become available for dengue virus infections and have the potential to be used for other flaviviruses [27]. The advantage of these assays is that they can be used throughout the early, middle, and late clinical course of infection with a sensitivity and specificity equivalent to PCR.

Virus isolation is key in understanding the virus and its effects on the vector and human population, but isolation is also the most challenging for laboratories. It requires serum from the early part of clinical illness, $-80{ }^{\circ} \mathrm{C}$ or colder freezers, and special laboratory techniques. Viral isolation requires inoculation of a small amount of serum into laboratory animals, arthropods like mosquitoes, or cell culture. Cell culture systems (vertebrate or insect cell cultures) are used for both virus isolation and neutralization titers.

In the study of material derived from patients, it is ideal to have acute and convalescent sera available. As demonstrated in Fig. 16.2, antibody titer rises rapidly from the acute to the convalescent serum, and a fourfold rise between the two samples is indicative of an acute infection. Demonstration of IgM in ELISA permits a presumptive diagnosis with a single serum.
Details of the techniques of $\mathrm{CF}, \mathrm{HI}$, and virus neutralization relating specifically to arboviruses are available in current manuals. Fluorescent antibody (FA) techniques, antigen-based ELISA, often coupled with monoclonal antibody, and PCR are widely used for antibody, antigen, and RNA detection, respectively. Such advances are greatly extending the scope of field and laboratory investigations.

\subsection{Genetic Sequencing}

Molecular methods such as polymerase chain reaction (PCR) and the ability to detect and amplify small amounts of RNA or DNA to identify specific pathogens have revolutionized our diagnostic capabilities in identifying patients who are acutely ill from flavivirus infections [28]. Reverse transcriptase PCR (RT-PCR) methods are highly sensitive and specific in detecting the infecting arbovirus during viremia [29, 30]. Real-time assays that utilize exonuclease fluorogenic assays such as TaqMan ${ }^{\circledR}$ (Applied Biosystems, CA, USA) and SYBR® Green (Molecular Probes, Inc., OR, USA) have significantly shortened the time of detection of RNA and DNA in a specimen but also added the ability to quantify the amount of virus and correlate it to disease severity [31]. Interest and need for point of care devices that can be utilized at a clinic with little expertise has prompted the development of new molecular platforms such as "isother- 
mal" methodologies including nucleic acid sequence-based amplification (NASBA), transcription-mediated amplification (TMA), and loop-mediated isothermal amplification (LAMP) technologies [32]. This allows an isothermal reaction and amplification to be performed at room temperature with potential reduction in time to detection to a matter of minutes.

Sequencing of the arboviruses has transformed our ability to understand the genetics and epidemiology of these viruses as well as the relatedness of each virus as demonstrated in Fig. 16.1. Genetic sequencing has rapidly evolved from a time-intensive process to technology for rapid full-length automated sequencing. Partial and full-length sequencing of the arboviruses has allowed phylogenetic analysis and revealed a series of clades defined by their epidemiology and disease associations [33]. Phylogenetic analysis has identified mosquito-borne, tick-borne, and noknown-vector (NKV) virus clades, which have been further divided into clades associated to their principal vertebrate host. Sequencing coupled with phylogenetic analysis is a powerful tool to understand the correlation between epidemiology, disease, and geography. It furthers our understanding of the complex evolutionary relationships between the virus, vector, and its vertebrate host. Metagenomics takes this concept further. It is the coordinated study of multiple genomes - the population of genetic material and, as applied to viruses, the entire community of viruses within the host environment [34]. This approach utilizes direct sequencing and bioinformatics to reconstruct the viral population and as such reveals the genetic diversity and evolution of the virus and its vector hosts. Especially powerful is the use of metagenomics when standard techniques fail to identify a viral infection, such as in emerging diseases. For example, metagenomics was used to identify specific viruses from samples collected from an enterovirus surveillance program in the Netherlands [34]. Samples were identified using conventional techniques including PCR that demonstrated cytopathic effects in cell culture without a virus. Metagenomics identified new viruses in all the samples.

\subsection{Mathematical Modeling}

Mathematical modeling is a powerful technique used to understand the interactions of the arbovirus, its vector, and host infection that produce endemic transmission or explosive epidemics in populations [35]. Mathematical models have the potential to predict epidemics and, equally importantly, to identify interventions by which to prevent or diminish the spread of the arbovirus through the use of vector reduction, personal protection methods, antivirals, or vaccines. Models have progressed from the basic susceptible, infected, and recovered SIR model to more advance modeling techniques using stochastic models in which the number of individuals in any class is an integer with events occurring randomly with a given probability based on the associated deterministic model. The value of stochastic models is the generation of different epidemics capturing the variability in the epidemic profile [35]. For example, a stochastic metapopulation model with spatiotemporal transmissibility scenarios was used to model the spread and transmission of yellow fever [36]. This model was useful to understand and assess the risk of yellow fever in producing urban outbreaks and to identify locations at risk for yellow fever introduction and subsequent transmission.

\section{Biological Characteristics of the Virus That Affect the Epidemiologic Pattern}

If you were to look at the world from the eyes of a flavivirus, you would find a bewildering array of environments you were forced to adapt and propagate in. The vector invertebrate environment is quite different from the vertebrate environment in requiring the virus to propagate at a lower body temperature and to utilize different cellular receptors for attachment and cellular entry. The virus upon infection of its vector host from a blood meal will replicate, escape from the midgut, evade vector host defenses, and replicate in high concentration in the salivary glands. Environmental factors including temperature and humidity affect vector longevity and viral replication and overwintering until the next transmission season. Upon infecting their vertebrate host after the bite of the infected vector, the flavivirus faces a new host environment with a different ambient temperature, new receptors for host cell entry and replication, and new host innate and adaptive immunity. Flaviviruses are remarkably adept and successful at adapting to an array of environments to replicate and produce infection and ultimately epidemics in human populations. Ultimately the biological characteristics of the flavivirus that affect human epidemiology rely on its ability to be successful in the host vector. The capacity of the virus to replicate in the vector is influenced by many factors including the environment, ecology, vector behavior, and viral molecular factors. The interaction of these factors is called the vectorial capacity. The extension of vectorial capacity to infect the host is known as vector competencethe intrinsic ability of a vector to become infected and to subsequently transmit a pathogen to a susceptible host [37].

The viral molecular factors involved in vectorial capacity and the ability of the virus to be highly specific for its vector host are determined by how arboviruses exist as a collection of variable genomes within a host known as a mutant spectrum, mutant swarm, or quasispecies [37]. During a replicative cycle, RNA viruses and its high mutation rate will develop as a distribution of genetic variants which is influenced by a balance between mutation and selection. Selection pressure will determine the most fit virus for the given environment with the least fit viruses going into 
extinction. This Darwinian survival of the fittest is known as viral adaptability. Genetic bottlenecks, defined as survival of a minority of one generation to become the majority of the next generation, can occur in flaviviruses and have been well described for dengue virus [38]. During the course of an infection in a vector, host genetic bottlenecks can occur, for example, when the virus leaves the midgut or replicates in the salivary glands allowing the selection of one mutant to become the dominant genotype. Thus, bottlenecks diminish viral diversity by selecting a subpopulation of viruses particularly adapted to that environment; as a result, frequent bottlenecks enhance the evolution of phenotypic robustness of the virus [37].

Viral fitness is inherently tied to vector fitness. A particular virus strain that is selected for rapid killing of its vector host will have little success at survival to its next host, and an attenuated virus that does not replicate well in its vector may not propagate to the vertebrate host. Viral replication may disrupt the physiology of the vector host through disruption of digestion, salivation, or changes in the vector midgut [39, 40]. Other consequences to vector fitness from viral infection include energy costs associated with immune activation, behavioral changes resulting in decreased feeding, and alterations in mating and propagation. A meta-analysis of studies across a range of mosquito-virus systems showed that arboviruses do reduce the survival of their mosquito vectors, but the overall impact on vector fitness varies by the virus taxonomic group and mode of transmission [41]. Alphaviruses, for example, were associated with the highest virulence levels in mosquitoes and the least for the bunyaviruses. The conclusion was that virus and vector fitness are interwoven and dependent on multiple selection factors that are evolving. The complexities of this relationship between virus and vector fitness coupled with the viral fitness required to propagate in a vertebrate host highlight the exquisite balance needed to maintain the life cycle and the disease process. This "trade-off" hypothesis suggests that the replication in arthropod then vertebrate hosts shapes virus evolution. It is when this trade-off results in an increase in both vectorial capacity and vertebrate infection that human epidemics, global expansion, and emerging diseases may occur. An example of this is the emergence of chikungunya virus (CHIKV) infection in 2004 from the Indian Ocean to India, attributed to a single amino acid mutation that enhanced vector capacity in a secondary vector Aedes albopictus [42]. Another example is the emergence of a new lineage of West Nile virus (WNV) in North America that was adapted for more efficient transmission in Culex mosquitoes [43]. When vectorial capacity for an arbovirus is diminished or vector resistance to virus infection is induced, virus transmission may potentially be completely interrupted. The occurrence of this phenomenon may been realized recently with the observation that infection of Aedes aegypti by Wolbachia, an intracellular bacterium, confers resistance of the mosquito to DENV infection [44]. These findings are now being used to infect natural A. aegypti mosquitoes to diminish DENV transmission [45].

\section{$5 \quad$ Epidemiology}

The epidemiology of flavivirus infections in humans as noted in previous sections is a complex interplay between viral evolution, selection pressures, vectorial capacity, and risk of human infection from the vector and its spread in human populations. In practical terms, many factors account for the dramatic changes in the epidemiology of the flaviviruses: increasing travel and the speed of travel where an individual can go from rural areas of Africa or Asia to major metropolitan areas in less than $24 \mathrm{~h}$, expanding trade and commerce, population growth, increasing urbanization and population detritus leading to increasing vector breeding areas, deforestation, and climate change [46]. Examples of this changing epidemiology are the spread of the dengue viruses throughout Asia, the Americas, and most recently Florida; resurgence of yellow fever in South America and Africa; spread of West Nile virus through North and Central America; and the spread of Japanese encephalitis in Southwest Asia [46].

\subsection{Incidence and Prevalence}

All infections with pathogenic flaviviruses discussed in this chapter are acute and can be diagnosed either through molecular means during the time of infection or by serology consistent with acute infection, i.e., detection of $\operatorname{IgM}$ antibody or a fourfold rise in antibody titer between acute and convalescent sera. Measurement of incidence requires documenting acute infection through the application of clinical criteria consistent with the flavivirus infection. All acute flavivirus infections progress from a classic presentation of fever, chills, myalgias, and headache to a more flavivirusspecific syndrome of an acute febrile illness, hemorrhagic fever, or encephalitis. These specific syndromes fall into a spectrum of overlapping clinical presentations, making it difficult to distinguish one flavivirus from another or from other pathogens based on clinical symptoms and signs alone.

All infections display a biological gradation ("iceberg") of clinical responses and disease severity both at a cellular and host response level (see Chap. 1). In the case of flaviviruses, although unobserved (below the "waterline" of the iceberg), subclinical infections are viremic and do contribute to the transmission and infection of the vector and thus represent a very important component of the epidemic. Further along the gradient of infection are mild ambulatory illness, moderate illness requiring medical care, more severe illness requiring hospitalization, and fulminant illness requiring intensive care with potentially fatal outcome. The shape of the gradient or "iceberg" varies among the flaviviruses and depends on the preexisting immunity in the population, vectorial capacity, and environmental factors. The subclinical infections are not well studied due to the requirement for long-term prospective studies of cohorts with the ability to diagnose asymptomatic infections. The best documentation of subclinical infection 
has come from the prospective cohort studies conducted in Northern Thailand where at least $50 \%$ of all DENV infections were subclinical $[47,48]$. In general, a large majority of flavivirus infections occur below the waterline of detection and subclinical. The more severe forms of infection resulting in death occur in less than $5 \%$ of all infections. Understanding the iceberg concept of infection is critical in thinking on the epidemiology and incidence of flavivirus infections. Surveillance confined to hospitalized cases will detect only 10-20\% of all cases. Extended to the ambulatory clinics, surveillance can detect an additional $30 \%$ of all infections. It is apparent that even with detection of $50 \%$ of acute cases, the incidence of infection is being grossly underestimated.

In contrast, seroprevalence studies (see Chap. 2) of flavivirus infection can define populations at risk, give a historical account of the transmission, and provide an estimate of the burden of infection in a population. A classic arbovirus seroprevalence study was the mapping of the worldwide distribution of yellow fever by Sawyer et al. in 1937 [49]. The virus neutralization test was performed using adult white mice as test animals. Yellow fever virus was found to be more widely distributed in South America and Africa than had been earlier suspected and was absent from Europe, Asia, and Australia. Neutralization tests measure durable antibody that persists for years. High rates of antibody prevalence could result from continued, widespread virus activity and/or from a large outbreak with a high attack rate. For example, yellow fever neutralization tests performed on sera collected from residents of Trinidad, West Indies, in 1953 revealed no immunes under the age of 15 years and therefore no apparent virus activity later than 1938. This situation changed dramatically with the reappearance of yellow fever on the island in epidemic form in 1954 [50].

Incidence and prevalence studies provide two views on flavivirus infection. The former can uncover newly occurring infections in the population and evidence of an outbreak; the latter offer a historical perspective on previous outbreaks and subpopulations that may be at risk. In most countries appropriate diagnostics are not available to diagnose a specific flavivirus infection, and clinical criteria are mostly used; as a result their population incidence is grossly underreported.

\subsection{Epidemic Behavior and Geographic Distribution}

Arbovirus infections are worldwide in distribution and may occur whenever the appropriate mosquito or other arthropod vectors abound in proximity to humans and a suitable amplifying host. Table 16.1 displays both the human pathogenic flavivirus and those where illness hasn't been documented, vector if known and human illness if known. The flaviviruses occur globally as both regional endemic diseases and epidemic diseases that can spread worldwide. The dengue viruses are now the most common mosquito-borne arboviral infection worldwide (http://www.who.int/csr/disease/dengue/en/). Other significant flaviviruses that have vast global distributions include West Nile virus, tick-borne encephalitis, and yellow fever. Regional flavivirus threats that produce epidemic diseases include Japanese encephalitis in Asia and West Nile virus and St. Louis encephalitis in North and South America. All are endemic diseases that produce transmission and disease every year with occasional epidemics.

\subsection{Temporal Distribution}

Temporal distribution is a consequence of overwintering and seasonal breeding and is region specific. If birds are the primary vertebrate host, temporal distribution is dependent on their migratory patterns, nesting, and hatching of young immunologically naïve chicks. In general, seasonal breeding of the vector occurs in spring, summer, and fall, although this is affected by the climate with warmer years having transmission during the winter months. Climate change and global warming will affect the temporal distribution of the flavivirus by changing the abundance of the vector. Global warming will increase the distribution of the vector as well as cause more rainfall and thus create more potential areas for breeding in the case of mosquitoes. The natural weather pattern that occurs approximately every 5 years, La Niña/El Niño-Southern Oscillation, or ENSO, can have dramatic effects on rainfall, flooding, and vectorborne diseases including the flaviviruses [51, 52]. This periodic climate change occurs across the tropical Pacific Ocean with variations in surface temperature (warming known as El Niño and cooling as La Niña). In a recent study, Murray Valley encephalitis virus (MVEV) in northern Australia and Papua New Guinea was monitored and correlated to the occurrence of rainfall [53]. Using multisatellite precipitation analysis, the authors found that increases in monthly rainfall and monthly number of days above average rainfall increased the risk of MVEV activity at a time lag of 2-3 months. Clearly climate change and weather have an effect on the temporal distribution of vector-borne infections with a particular impact on the flaviviruses.

\subsection{Age, Sex, and Other Demographic Factors}

Infections with arboviruses can occur at any age. The age distribution depends on the degree of exposure to the particular transmitting arthropod relating to age, sex, occupation, and recreational habits of the individual or group of individuals. In highly endemic areas where transmission occurs every year, such as with Japanese encephalitis and dengue viruses, flavivirus infection is seen primarily in children, with adults 
protected by the antibody from previous infections [54, 55]. In areas where transmission is sporadic and the entire population is at risk, extremes of age becomes a risk for severe infection such as seen in WNV infection in adults over the age of 50 years [56].

\subsection{Other Factors}

Genetic factors are known to influence disease severity from flavivirus infection and thus directly the epidemiology of arbovirus infections. Nutrition may have an effect on increasing disease severity in specific flavivirus infections such as in dengue hemorrhagic fever though it is unknown if there is an effect with other infections [57]. Certainly malnutrition can suppress the immune response and affect disease severity and thus the epidemiology. Genetic factors are very likely associated with disease severity. For example, in casecontrol gene association studies performed on cohorts of DENV-infected patients in Asia and the Caribbean, specific genes have shown associations with disease severity. These genes include the HLA molecules, the cell receptors for IgG (FcGII), vitamin D, and ICAM3 (DCSIGN or CD209) [58]. Also pathogen recognition molecules such as mannosebinding lectin (MBL) have associated with disease severity as well as the blood cell-related antigens including ABO and human platelet antigens (HPA1 and HPA2) [58]. African slaves were long known to be immune from the severity of yellow fever and were recruited to help stricken victims during the Philadelphia 1793 yellow fever epidemic [11]. Clearly genetics that determine both acquired and innate immune responses contribute to disease severity or protection from flavivirus infections and can affect the epidemiology of these infections.

\section{Mechanism and Route of Transmission}

By definition, the flaviviruses as arboviruses must be transmitted by arthropod vectors within which multiplication of the virus is a necessary requirement. Non-arthropod-related transmission to humans can occur such as through goat, sheep, or cow milk in the case of TBEV and respiratory and alimentary tract with Omsk HF [59, 60]. The primary vectors are mosquitoes and ticks. The duration of the necessary period of virus multiplication within the arthropod host before it becomes infectious varies from virus to virus and vector to vector and is also directly temperature dependent. For most viruses under average summer temperature conditions, the extrinsic incubation period falls in the 7- to 14-day range. Once infected, vectors may remain infected and able to transmit for many weeks or months. In the case of ticks, this infection may be years. Transmission of virus transovarially in arthropods, often referred to as "vertical transmission," has been demonstrated (specific examples, tick-borne encephalitis in ticks, DENV in mosquitoes). Venereal transmission of SLE viruses in vector mosquitoes has also been described. These mechanisms may be important for survival of some arboviruses in nature, permitting overwintering or survival over a protracted dry spell. Birds are important reservoir vertebrates for the viruses of JEV, WEE, and SLE.

There are a number of flaviviruses that cause human infections where the principal vector species is not known (Table 16.1). These include the viruses Apoi, Dakar bat, Koutango, Modoc, and Rio Bravo. More research is needed to establish the principal vector or, if not found, to gather details on their mode of transmission.

There are two nonvector modes of transmission to humans of the vector-borne flaviviruses that is essential to know-transfusion mediated and sexual. During the 2002 WNV epidemic in the United States, 23 patients were confirmed to have acquired WNV through transfused contaminated blood products [61]. Of these the majority were immunocompromised due to transplantation or cancer. Sixteen donors with evidence of WNV viremia at donation were linked to the 23 infected recipients. As a result of these findings, the US blood supply is now screened for WNV. Sexual transmission of another normally vector-borne flavivirus was recently documented. Zika virus (ZIKV) is a mosquito-transmitted flavivirus that has been isolated from sick persons in Africa and Southeast Asia. Two American scientists working in Senegal became acutely ill with ZIKV [62]. One of the scientists upon returning to the United States infected his wife who developed confirmed ZIKV symptomatic infection. Because she never traveled outside of the United States, direct person-to-person transmission was thought to be the mode of infection either through saliva or infected semen.

\section{$7 \quad$ Pathogenesis and Immunity}

Arbovirus infections are usually transmitted by the bite of the appropriate vector, and the skin is the normal portal of entry. Even before the virus enters the host through the skin, an important cofactor contributed by the vector assists in shaping virus entry. Saliva from arthropods (i.e., ticks and mosquitoes) has been shown to potentiate flavivirus infection and enhance in vertebrate hosts. Virus and arthropod saliva are delivered into the skin of the vertebrate host. Arthropod saliva contains a complex mixture of bioactive molecules that are capable of altering homeostasis, immune response, and dendritic cells and may contribute to the ability of flaviviruses to establish an infection [63]. The potentiation of flavivirus infection 
by arthropod saliva has been demonstrated for a number of viruses including WNV and saliva from Culex tarsalis which resulted in enhancement of early WNV infection in vertebrate hosts [64].

The first cells that typically come in contact with flaviviruses are skin dendritic cells (DCs). These cells have been shown to be important initial targets of infection that shape the immune response for many of the pathogenic flaviviruses including DENV, YFV, and tick-borne encephalitis virus (TBEV) [50, 65-67]. TBEV targets DCs early in infection and are major inducers of interferon (IFN) and the innate immune response. TBEV modulates DCs and thus shapes the innate response via INF antagonism. DCs become infected and transport the virus to draining lymph nodes promoting virus dissemination. After viral replication in target cells, the virus becomes widely disseminated throughout the host. Viremia in the host is an important determinant for additional infection in noninfected biting arthropods. The degree of viremia determines if the vertebrate host becomes a "dead-end host" where viremia with agents such as JEV and WNV is minimal and no additional biting vectors are infected. In other flaviviruses, high and sustained viremia provides a source of additional vector infection, as is the case for DENV where humans are the primary reservoir for infection.

The site of multiplication of most arboviruses remains undetermined but is presumed to be in the vascular epithelium and the reticuloendothelial cells on the lymph nodes, liver, spleen, and elsewhere. Liberation of virus from these organs constitutes the "systemic phase of viremia," resulting after 4-7 days in fever, chills, and aching joints. A number of arbovirus infections have two phases-this early phase and then a second phase with or without a few days of freedom from symptoms. The second phase may be attended by encephalitis, joint involvement, rash, hemorrhage, and involvement of the liver and kidneys. In most arbovirus infections, only the first phase occurs, and the disease is mild and "nonspecific." In other instances, the early phase may be missed, and only the severe manifestations occur. The early phase is accompanied by leukopenia and the second phase often by leukocytosis. Tissue injury may be the direct effect of viral multiplication in susceptible cells, as is the case with liver involvement in yellow fever.

Humoral antibodies regularly appear early in the course of arbovirus infection and constitute the major basis of immunity. Such immunity may be lifelong. No infection with yellow fever virus has been recorded in an individual who either had antibodies from an earlier infection or had a history of yellow fever vaccination with development of postvaccination antibody. The presence of antibodies in the blood at the time of exposure to an infected arthropod vector provides a primary deterrent to reinfection with the homologous virus.

\section{Patterns of Host Response}

\subsection{Clinical Features}

Inapparent and subclinical human host responses predominate in most arbovirus infections. Clinical illness is frequently the exception rather than the rule. This varies from virus to virus. For example, infection with WNV, SLEV, and JEV viruses results principally in mild and inapparent infections, whereas in infection with YFV, the host response is likely to be clinically apparent and often severe (Table 16.2); the reasons for these differences are not known.

\subsection{Diagnosis}

Cases of arbovirus infections are not likely to be diagnosed unless there is a high degree of clinical suspicion. Outbreaks of encephalitis in horses and dying off of birds may be an early warning sign from some arboviruses. Recognition of the arbovirus infection acquired by the traveler outside the United States also depends on the alertness of the examining physician. Rapid jet transport now permits exposed overseas travelers to reach home and fall sick even within the short incubation period of such infections. The physician must maintain a high degree of suspicion when seeing central nervous system, influenza-like illnesses, or hemorrhage with fever occurring in travelers recently returned from areas endemic for arboviruses. Diagnosis will require specimens (serum, cerebrospinal fluid) to be sent to specific laboratories that have the capacity to perform the required assays such as the state laboratory or the Centers for Disease Control (CDC).

The laboratory diagnosis depends on the isolation of the virus from the blood and/or a fourfold antibody rise in titer or presence of specific IgM in sera taken during the acute and convalescent phases of illness. Often, the suspicion of an arbovirus infection in individual cases arises too late for

Table 16.2 Patterns of host response to arbovirus infections in man

\begin{tabular}{ll}
\hline Response & Examples $^{\mathrm{a}}$ \\
\hline Asymptomatic infection & WNV, DENV, JEV, SLEV \\
\hline Mild febrile illness & SLEV, YFV, JEV, DENV \\
\hline $\begin{array}{l}\text { Influenza-like illness with aching } \\
\text { and joint pains }\end{array}$ & DENV, ZIKV \\
$\begin{array}{l}\text { Encephalitis, mild } \\
\text { Encephalitis, severe }\end{array}$ & WNV, TBEV, SLEV \\
\hline $\begin{array}{l}\text { Jaundice, proteinuria } \\
\text { Rash, sometimes with hemorrhagic } \\
\text { manifestations }\end{array}$ & YFV \\
\hline Shock syndrome & AHFV, DENV, KFDV \\
\hline
\end{tabular}

${ }^{a}$ Certain viruses have been selected for this list particularly to illustrate the range of symptoms that may be seen in populations infected with a single virus 
virus isolation or for demonstration of a rise in antibody titer. Often only one acute serum specimen is sent without a convalescent specimen. Under these circumstances, the presence of a high antibody titer in a single serum may be significant if the infection is an uncommon one in that region and particularly if antibody surveys reveal a low antibody prevalence or if prior surveys have demonstrated the absence of antibody in that community. The appropriate procedure in suspected cases is to (1) notify the health department and seek background epidemiologic and clinical data and (2) send acute and convalescent serum samples to the nearest public health laboratory (usually a state laboratory), with a request for antibody tests for arboviruses and other encephalitis-producing viruses. Some state laboratories may not provide this testing, so a request for transshipment of sera to the CDC might be included.

\section{Control and Prevention}

Major control methods include (1) control of the arthropod vector, which may be by elimination of breeding sites, termed source reduction, or modification of them by application of insecticidal substances or by direct attack on the adult arthropods through residual insecticide treatment of adult resting places; (2) avoidance of exposure to vector bites by screening of houses, by use of protective clothing, and by application of insect repellent sprays or creams when outside in high-risk areas; and (3) immunization, a procedure widely used only for yellow fever, TBEV, and Japanese encephalitis in endemic areas.

Control of vectors through biological approaches ranges from introduction of competing species such as the use of parasites lethal to the vector including protozoa, helminths, bacteria, and viruses to introduction of genes deleterious to the vector population or influencing the vector behavior or capacity to be infected with a pathogen [68].

\section{Characteristics of Selected Pathogenic Flaviviruses}

Selected flaviviruses are discussed in this section and focused on those that produce human infections and represent emerged or emerging infection or have the potential to become global health problems. This section is organized by vector into tick-borne, mosquito-borne, or viruses with no known vector (see Table 16.1). Under the tick-borne flaviviruses are the mammalian tick-borne virus complex (tick-borne encephalitis, Gadgets Gully virus, Kadam virus, Kyasanur Forest disease, Alkhurma virus, Langat virus, Omsk hemorrhagic fever, Powassan virus, Royal Farm virus, and Louping ill virus). Under the mosquito-borne viruses are the Aroa virus, Japanese encephalitis virus, Kokobera virus, Ntaya virus, Spondweni virus, and the yellow fever virus complexes. Under the viruses with no known arthropod vector are the Entebbe bat virus complex, Modoc virus complex, and Rio Bravo virus complex. For each of the viruses, the epidemiology, vector, human disease, diagnosis, and epidemic potential will be briefly covered.

\subsection{Tick-Borne Viruses}

\subsubsection{Mammalian Tick-Borne Virus Complex}

The mammalian tick-borne virus complex, a genetic and antigenically related group of viruses, share similar features and have ticks as their vector and animal vertebrates as a reservoir [69]. These viruses are pathogenic to humans producing a range of diseases to include a mild febrile illness, severe hemorrhagic fever, and encephalitis and contain viruses that have emerged or emerging as global health problems. Some viruses, such as the agent of Kyasanur Forest disease, remain localized to specific geographic areas and have the potential to emerge as regional health threats. The mammalian tick-borne virus group includes Omsk hemorrhagic fever virus (OHFV), Langat virus (LGTV), Alkhurma hemorrhagic fever virus (AHFV), Kyasanur Forest disease virus (KFDV), Powassan virus (POWV), Royal Farm virus (RFV), Karshi virus (KSIV), Gadgets Gully virus (GGYV), and Louping ill virus (LIV) [2].

\section{Gadgets Gully Virus (GGYV)}

GGYV was first isolated from Ixodes uriae on the penguin rockeries of Macquarie Island, Australia, in 1976 [70]. Six other strains were isolated from the same location in 1976 and 1977. To date GGYV has not been known to be a cause of human disease.

\section{Kyasanur Forest Disease Virus (KFDV)}

KFVD, also known as monkey fever, is a disease of man that is transmitted primarily by Haemaphysalis ticks in the tropical deciduous forests of the Karnataka State in South India [71]. Its subsequent discovery in the Yunnan Province, China, in 1989, called Nanjianyin virus, is now known as a subtype of KFDV [72]. Results of a 1987-1990 seroepidemiologic investigation in the Yunnan Province demonstrated that residents of the Hengduan Mountain region had been infected with this virus [72]. This suggests that KFDV may have a wider geographic distribution, and migratory birds with attached infected ticks may be responsible. At-risk populations for KFDV include persons with recreational or occupational exposure to the forests in Karnataka, India. Human disease may be accompanied by outbreaks of hemorrhagic disease in forest monkeys maintained in a sylvatic cycle. After an incubation period of 3-8 days, the 
symptoms of KFDV infection are fever, headache, severe muscle pain, cough, dehydration, and gastrointestinal symptoms. After 1-2 weeks of symptoms, some patients recover while most patients experience severe hemorrhagic fevers with a 2-10\% fatality [73]. Treatment is supportive care. A formalin-inactivated virus vaccine produced in chick embryo fibroblasts is licensed and available in India [74-77].

\section{Alkhurma Hemorrhagic Fever Virus (AHFV)}

AHFV has been isolated several times since 1995 from the blood of patients with severe hemorrhagic fever in Saudi Arabia. It is associated with the camel tick. Among 16 patients, 4 had lethal outcome [78]. Sequence analysis revealed the close genetic relationship of this virus to KFDV [79]. AHFV may be an emerging infection and a risk to travelers based on a report of tourists visiting southeastern Egypt near the border of Sudan who were infected by AHFV and developed hemorrhagic illness [80]. Like KFDV, AHFV may have its origin in Africa and in the case of AHFV transported from Africa and other countries to Saudi Arabia by the transport of camels and other livestock carrying infected ticks [80].

\section{Karshi Virus (KSIV)}

KSIV has been isolated from Ornithodoros papillipes ticks from Karshi, Uzbekistan. It has been reported in the Russian literature as a cause of encephalitis in humans though the exact numbers are not known (Dr. S. Khodjaev, personal communication). The vector competence of human isolates of KSIV was tested in a variety of mosquitoes and ticks. KSIV replicated in and was transmitted by all three species of Ornithodoros ticks tested (O. parkeri, O. sonrai, and $O$. tartakovskyi) [81]. Experiments demonstrated that when inoculated with Karshi virus, $90 \%$ of Ornithodoros ticks transmitted this virus to suckling mice and transmission continued for at least 1 year [81]. Female O. tartakovskyi transmitted KSIV vertically to their progeny. This study suggests that Ornithodoros spp. are potential vectors and rodent species a possible reservoir, with the tick responsible for the long-term maintenance of KSIV in the environment.

\section{Royal Farm Virus (RFV)}

RFV was first isolated from Argas hermanni nymphs from Kabul, Afghanistan, by the US Naval Medical Research Unit in Cairo, Egypt [82]. Its group relation to Powassan and Langat viruses was demonstrated by complement fixation $(\mathrm{CF})$ and neutralization tests $(\mathrm{N})$. By CF test it is closely related to Powassan and by $\mathrm{N}$ test to Langat. RFV has never been found to be a cause of human disease.

\section{Langat Virus (LGTV)}

LGTV was first isolated in Malaysia and Thailand from pools of ticks of Ixodes granulatus and Haemaphysalis spp [83].
Although wild-type LGTV has never been found to cause human disease, patients with terminal malignancies were inoculated with LGTV in a clinical study hoping the virus might produce remission. The investigators also thought that data from this study might also support the use of LGTV as a live virus vaccine candidate against other tick-borne flaviviruses in healthy individuals. In this study, LGTV administered subcutaneously was able to produce viremia, fever, and leukopenia [84]. Further studies on this as a viable human vaccine are limited.

\section{Louping III Virus (LIV)}

Louping ill virus is a zoonotic disease of livestock on the British Isles transmitted by the tick Ixodes ricinus. It is also a very rare cause of disease in humans for people who work closely with sheep or the virus. There have been over 30 human cases of disease from LIV and several cases of laboratory-acquired infections [85, 86]. Four clinical syndromes can be seen in human disease to include influenzalike illness, a biphasic encephalitis, a poliomyelitis-like illness, and a hemorrhagic fever [86].

\section{Omsk Hemorrhagic Fever Virus (OHFV)}

$\mathrm{OHFV}$ is a significant cause of hemorrhagic fever and encephalitis in Western Siberia. While the disease may be transmitted by Dermacentor ticks, outbreaks related to direct human contact with the virus from muskrat trapping and skinning may occur [78]. The most marked clinical sign of this disease is hemorrhage, but clinical symptoms also include diffuse encephalitis which disappears during the recovery period [78].

\section{Powassan Virus (POWV)}

POWV is a tick-transmitted virus of the tick-borne encephalitis subgroup of flaviviruses. It is antigenically related to TBEV discussed below. POWV is a North American virus and originally isolated from the brain of a child who died in Ontario in 1959 [87]. Powassan virus has been found to be widely distributed in small mammals in Canada and the northern states of the United States including New York, Wisconsin, and Minnesota [88]. POWV was originally thought to be a minor cause of human encephalitis with 27 cases reported in Canada and the northeastern United States during 1958-1998 [89]. Over the past decade there has been an expansion of cases throughout Canada and the United States with four Maine and Vermont residents with encephalitis found to be infected with POWV in 1998-2001. During 1999-2005, there were nine cases of serologically confirmed POWV disease: four from Maine, two from New York, and one each from Michigan, Vermont, and Wisconsin [89, 90]. The Michigan and Wisconsin cases represent the first reported from the north-central United States and suggest that this infection may be underreported in the United States. 
POWV encephalitis is characterized as a classic encephalitis with the acute onset of muscle weakness, confusion, and neurologic signs. All patients described in this series recovered but most had long-term neurologic sequelae. POWV is transmitted by hard ticks (Ixodidae spp.). Diagnosis can be accomplished by serology and PCR. There is no vaccine available for POWV or specific therapy for illness.

\subsubsection{Tick-Borne Encephalitis}

Tick-borne encephalitis virus (TBEV) produces a fatal encephalitis in Europe and Asia [91]. The disease has been known under several names, including Russian spring-summer encephalitis and Far Eastern encephalitis. Clinically, TBEV produces an acute febrile illness followed by encephalitis with a high mortality rate. The virus is maintained in an environmental cycle involving small mammals and birds in forested regions and transmitted by the ticks Ixodes ricinus and I. persulcatus. Humans become infected by the bite of infected ticks. Forest and construction workers, woodsmen, trappers, and farmers are at highest risk. TBEV is an emerging infection spreading geographically and increasing in mortality. From 1974 to 2003 there was a $400 \%$ increase in morbidity in Europe and has spread to regions that were previously unaffected $[92,93]$. TBEV is a notifiable disease in 16 European countries. There was an average of 8,755 reported cases of TBEV per year in Europe and Russia between the years 1990 and 2007 as compared to 2,755 cases per year between 1976 and 1989 [94]. The expansion of TBEV may be caused by changes in the number and geographic range of the tick vector due to climate changes and changes in land use. No specific therapy exists for TBEV. Prevention from infection is through control of tick populations, protection against tick bite (repellents, protective clothing), and avoidance of tick habitats. An inactivated vaccine is widely used in central Europe. Diagnosis is made by serology, virus isolation, and PCR.

\subsubsection{Mosquito-Borne Viruses}

The mosquito-borne viruses represent some of the most pathogenic viruses known to man. They have been historically a cause of large epidemics and have become emerging or emerged pathogens. They produce a range of illnesses from a severe febrile illness to fatal hemorrhagic disease and encephalitis. As mosquito-borne viruses the majority have an intermediate bird or rodent reservoir with humans infected by the bite of infected mosquitoes.

\section{Aroa Virus Complex}

Aroa Virus (AROAV)

AROAV was initially isolated from a hamster (Cricetus auratus) in the vicinity of the Aroa River, Venezuela, in the early 1970s. Complement fixation (CF) experiments con- cluded Aroa was a new group B virus most closely related to Bussuquara virus. Antigenic and biological properties categorize AROAV closely with Israel turkey meningoencephalitis, Koutango, and Negishi viruses. AROAV grows in C6/36 cells suggesting vector transmission potential [95]. There are no reports of human infection or disease [3].

Bussuquara Virus (BSQV)

BSQV was isolated in 1956 in Belem, Brazil, from a howler monkey (Alouatta belzebul). The virus has been isolated in the Amazon from sentinel and wild Proechimys spp. rodents and Culex mosquitoes [96]. The virus was known to circulate in Brazil, Colombia, and Panama [97]. In vitro experiments demonstrate infection across a range of murine, chick, and monkey cell lines [98]. Both Aedes and Culex mosquito species demonstrate a potential for infection. Liver lesions similar to those caused by YFV were noted in an infected howler monkey, Alouatta belzebul. There has been one human clinical case reported with fever, headache, profuse sweating, and arthralgia lasting 4 days [3, 99].

\section{Iguape Virus (IGUV)}

IGUV was isolated in 1979, from a sentinel mouse, in the rain forest of Iguape county, Sao Paulo state, Brazil [96, 100]. Serosurveys demonstrate wild birds may participate in the virus transmission cycle, as may rodents and marsupials. Defining virus reservoir-vector relationships requires further study [100]. There have been no known human infections.

\section{Naranjal Virus (NJLV)}

NJLV was first isolated from a hamster in 1976 in Guayaquil, Ecuador. It is closely related to BSQV, but CF and neutralizing antibody assays clearly demonstrate that it is distinct [101]. Experimental infection of mice produces death and viremia over 5.6-8 days [3]. There are no reports of human infection or disease.

\section{Japanese Encephalitis Virus Complex}

\section{Cacipacore Virus (CPCV)}

CPCV was first isolated from the Formicarius analis (blackfaced ant bird) in Oriximina, Para, Brazil, in 1997 [102]. Serosurveys demonstrate evidence of infection in wild birds, rodents, bats, and humans. Injection into mice produces death [102]. A 33-year-old farmworker in the Brazilian state of Rondônia, Brazil, was admitted to intensive care with suspected leptospirosis and yellow fever; however, viral sequencing identified CPCV as the cause of infection [103].

\section{Koutango Virus (KOUV)}

KOUV was initially isolated in 1968 from a Tatera kempi (gerbil) in the Koutango Village, Saboya region, Dakar, Senegal. KOUV is known to circulate in Senegal, Central 
African Republic, Somalia, and Gabon [104, 105]. Natural host range includes rodents, ticks, mosquitoes, and a single case of infection in man (laboratory accident). Mosquito (Aedes aegypti) transmission and reinfection experiments have been conducted as well as experimental transovarial transmission which suggest $A$. aegypti is a competent vector $[3,106]$.

\section{Japanese Encephalitis Virus (JEV)}

JEV is the leading cause of viral encephalitis in Asia [107]. $\mathrm{JEV}$ is a mosquito-borne zoonotic flavivirus transmitted predominantly between birds and mammals and to humans by mosquitoes. The principal vector of JEV in northern Asia is the rice paddy-breeding Culex tritaeniorhynchus summarosus and in southern Asia C. tritaeniorhynchus and related C. vishnui group. Many species of wild birds function as reservoirs, supporting JEV circulation and transmission. Domestic pigs may serve as amplifying hosts. Horses and humans are dead-end hosts because the virus circulates in blood at low levels and for a short duration, thereby not supporting transmission $[108,109]$.

Outbreaks of JEV occurred regularly in Japan, Korea, China, and Taiwan during the twentieth century. Seasonal outbreaks now involve portions of Vietnam, Thailand, Nepal, and India. The Philippines, Indonesia, and the northern tip of Queensland, Australia have witnessed smaller outbreaks [108, 109]. Large-scale vaccination programs made it possible for Japan, Korea, and Taiwan to nearly eliminate JEV. More recent vaccine adopters (Thailand, Sri Lanka, and Nepal) have also observed a reduced disease burden $[108,109]$. Numerous JEV endemic regions remain at risk despite the availability of safe and efficacious JEV vaccines.

In JEV endemic areas, the incidence of disease is greater in the young; attack rates in the 3- to 15-year age group are five to ten times higher than in older persons; this is likely a herd-immunity phenomenon [108, 109]. Numerous studies and epidemiologic observations document a weak protective effect of prior dengue virus infection on subsequent JEV disease $[110,111]$. The ratio of symptomatic JEV cases to infections varies between 1:25 and 1:300 with the lower rates (1:200-1:300) observed in Asians indigenous to areas with enzootic JEV transmission, while higher rates were measured in American military personnel [112-114]. The incidence of JEV for travelers from non-endemic countries to Asia is estimated at $<1$ case per million travelers. Expatriates and travelers who spend prolonged periods in JEV enzootic areas may share a similar or higher risk than the indigenous population [115-117]. Between 1973 and 2008, 55 cases of JEV were reported in travelers from non-endemic countries. Ten $(18 \%)$ of these were fatal and $44 \%(N=24)$ recovered but experienced sequelae [115-124].
JEV is a small $(50 \mathrm{~nm})$, enveloped virus containing a 10.7-kb, single-stranded, positive-sense RNA genome. The viral envelope (E) protein serves as the cell receptor-binding protein and the fusion protein for virus attachment and entry into host target cells. Antibodies directed against E protein neutralize the virus and play an important role in protection $[109,125,126]$. The JEV was first isolated from the brain of an encephalitis patient in Tokyo (1935) and was virologically and serologically established as the prototype (Nakayama) strain [127]. Antigenic variation among JEV strains has been shown by serologic, virologic, and monoclonal antibody analysis [127-129]. The virus causes cytopathic effect (CPE) in varied cell lines that include chick embryo, human epithelial, mouse, Vero, LLC-MK2, and C6/36. A broad range of hosts experience encephalitis and death following intracranial or intraperitoneal administration of JEV to include mice, hamsters, dogs, foxes, cats, and goats. Asymptomatic viremia is observed in monkeys, guinea pigs, rabbits, chickens, pigs, and bats [3]. Culex tritaeniorhynchus, C. fuscocephalues, and C. gelidus were experimentally infected feeding on viremic pig and chicken and successfully transmitted infection to chicken [130-133]. Transovarial transmission was demonstrated in Aedes albopictus and A. togoi [134].

Following infection there is a 5- to 7-day incubation period and then a nonspecific viral prodrome. Early clinical symptoms include lethargy, fever, headache, abdominal pain, nausea, and vomiting [135]. Nuchal rigidity, photophobia, altered consciousness, hyperexcitability, masked facies, muscle rigidity, cranial nerve palsies, tremulous eye movements, tremors, involuntary movement of the extremities, paresis, incoordination, pathological reflexes, and meningeal (meningitis), parenchymal (encephalitis), or spinal cord (myelitis) signs may follow [136]. Sensory deficits are rare, and children (50$85 \%$ ) experience focal or general seizures more often than adults $(10 \%)$ and are associated with poor clinical outcome [136]. In a recently published study of 1,282 adult patients collected from 4 JEV epidemics in India $(1978,1980,1988$, and 1989), altered sensorium occurred in $96 \%$, convulsions in $86 \%$, and headache in $85 \%$ [137]. Hyperkinetic movements were noted in $46 \%$, and most $(83 \%)$ were choreoathetoid in nature. Opsoclonus (20\%), gaze palsies (16\%), and pupillary changes $(48 \%)$ were observed, but cerebellar signs were not. Dystonia and decerebrate rigidity were observed in 43 and $6 \%$, respectively, of patients with $17 \%$ having paralytic features and seizures in $30 \%$. Abnormal breathing patterns, pulmonary edema, and upper gastrointestinal hemorrhage were observations of prognostic importance.

Elevated peripheral white blood cell counts and low sodium may be observed. Cerebrospinal fluid (CSF) opening pressure, white blood cell content, and protein levels may be normal or mildly elevated [136]. Electroencephalogram may demonstrate diffuse delta wave activity and, rarely, seizure 
patterns [136]. Imaging studies may demonstrate abnormal findings in the white matter, thalamus, basal ganglia, cerebellum, midbrain, pons, and/or spinal cord.

If the patient improves, it will typically begin about 1 week after symptom onset at the time of defervescence, but recovery of neurologic function may take weeks to years. Seizure disorders, motor and cranial nerve paresis, and movement disorders may persist in up to one third of patients. Persistent behavioral and/or psychological abnormalities occur in 45-75\% of survivors and are more severe in children [138]. JEV is managed with supportive care as there are no specific antivirals demonstrating clear benefit. Fatality rates vary between 5 and $40 \%$ and are often reflective of medical care resources and capabilities.

Diagnosis by viral isolation is infrequent although feasible from brain tissue in fatal cases or CSF in about one third of cases during the acute infection period; this portends a bad prognosis [139]. Serologic diagnosis is possible, demonstrating a fourfold rise in antibody titer using hemagglutinin inhibition, complement fixation, or neutralizing antibody assays with appropriately timed acute and convalescent specimens. Serum IgM antibodies appear early in the course of infection, persist for 3-6 months, and are relatively specific. The IgM-capture ELISA is especially well suited for diagnosis by detection of locally synthesized JEV antibody in the CSF [140]. Earlier and more vigorous antibody responses correlate with improved survival. Serologic assays are plagued by cross-reactivity between JEV and other flaviviruses such as dengue and West Nile virus. Newer serologic, reverse transcriptase polymerase chain reaction and NS1 protein-based assays tout improved sensitivity and specificity.

Individuals can reduce exposure to vectors by use of mosquito repellant, wearing long-sleeved shirts and trousers, avoiding outdoor activities in the evening, and sleeping under permethrin-impregnated mosquito nets or in screened or airconditioned rooms [141]. Active immunization, in addition to personal protective measures, is the optimal strategy for preventing JEV. JEV vaccines have been available since the 1950s [135]. Early vaccines were produced by inactivating virus grown in mouse brain or in primary hamster kidney (PHK) cells [135]. These vaccine constructs were used in the United States and Europe (BIKEN; distributed as JE-Vax by Sanofi Pasteur, Lyon, France) [142]. Seroconversion rates (i.e., quantitative neutralizing antibody titers following vaccination) and efficacy varied according to the population studied (indigenous vs. nonindigenous to JEV endemic area) and number of doses administered (one, two, or three doses) in the primary immunization series [135, 143]. Prolific vaccine use has contributed to significant decreases in JEV incidence in Thailand, India, Korea, Taiwan, Vietnam, and areas of Malaysia and Sri Lanka [135]. Since 1989, numerous cases of moderate to severe hypersensitivity-type reactions temporally associated with JEV vaccination have been reported, some resulting in hospitalization [144, 145]. The cause of the reactions is unclear, but the presence of murine neural proteins, gelatin, and/or thimerosal in vaccine preparations has been implicated, but not proven. More serious was the case in Japan of acute disseminated encephalomyelitis (ADEM) temporally related to vaccination. ADEM has been reported as a severe drug reaction following administration of inactivated mouse brain vaccine in $5 \times 10^{-4}$ to $1 \times 10^{-6}$ administered doses [143]. No definite increased risk of ADEM temporally associated with JEV vaccination has been proven.

To move away from mouse brain-derived vaccines, vero cells were adopted for the development of numerous JEV vaccine candidates [135]. Widespread distribution and use in Asia have demonstrated an excellent safety profile, immunogenicity, and efficacy [146]. Second-generation JEV vaccines with improved safety profiles and lower dosage requirements present new options for immunization [135]. The IC51 (IXIARO®, in Australia and New Zealand available as JESPECT; Intercell AG, Vienna, Austria) vaccine is a purified, formalin-inactivated, whole-virus JEV vaccine. The product is approved in the United States (persons aged $\geq 17$ years), Europe, Canada, Switzerland, and Australia. IC51 is manufactured by Intercell Biomedical (Livingston, United Kingdom) and is distributed in the United States by Novartis vaccines (Cambridge, Massachusetts). The vaccine construct, developed at the Walter Reed Army Institute of Research (Silver Spring, MD), is based on a SA14-14-2 virus strain passaged in primary dog kidney (PDK) cells, cultivated in Vero cells, and formulated with aluminum hydroxide [147]. Numerous clinical trials have demonstrated IC51 safety and immunogenicity [148, 149]. A pooled, 6-month safety analysis of seven phase III trials included 3,558 subjects with at least one IC51 vaccination, 435 subjects with a JE-Vax® vaccination, and 657 with phosphate buffered saline solution with $0.1 \% \mathrm{Al}(\mathrm{OH}) 3(\mathrm{PBS}+$ Alum) control vaccination demonstrated a similar safety profile between the study arms with a superior local reactogenicity profile for IC51 compared to JE-Vax $®$ [150]. Individuals previously given tick-borne encephalitis (TBE) vaccine and then vaccinated with IC51 demonstrated a $17 \%$ higher incidence of at least one adverse event in volunteers with previous TBE vaccination and slightly higher seroconversion rates and higher GMT in the IC51 group who had received TBE vaccination (98\%, 470, compared to $92 \%, 182$ ) [151].

Sanofi Pasteur has developed a JEV vaccine based on a construct created at the St. Louis University Health Sciences Center, St. Louis, Missouri, and Acambis Inc., Cambridge, Massachusetts [152]. JEV-CV is produced by inserting prM and $\mathrm{E}$ genes from the SA14-14-2 JEV virus into the YFV $17 \mathrm{D}$ viral strain "backbone" containing the YF nonstructural genes [153]. The resulting chimeric RNA is electroporated into Vero cells and replicated by the highly stable YFV RNAdependent replicase. The safety and immunogenicity of a 
single dose of JEV-CV at two concentrations $(1 \times 5.0$ log${ }_{10} \mathrm{PFU}$ versus $\left.1 \times 4.0 \log _{10} \mathrm{PFU}\right)$ was comparable to licensed YFV-VAX $\left(1 \times 5.0 \log _{10} \mathrm{PFU}\right)$ in a phase 1 trial. Low-level viremias were observed in both JEV-CV groups, and the frequency of all adverse events was similar in each group. Overall, $96 \%$ of subjects who received JEV-CV developed neutralizing antibodies to one or more of the wild-type JEV strains tested (Beijing, P3, Nakayama), and all developed antibodies to the homologous strain [154]. There is evidence that JEV-CV induced sterilizing immunity. Safety and immune responses were evaluated in $N=10 \mathrm{JEV}-\mathrm{CV}(1 \times 4.0$ $5.0 \log _{10} \mathrm{PFU}$ ) vaccine recipients who, about 9 months later, were given a single dose of JE-Vax. No severe adverse events were noted and seroconversion rates rose from $50 \%$ pre-JEVax to $90 \%$ with a GMT greater than 1:150. Phase 3 studies assessed safety and immunogenicity comparing JEV-CV and a mouse brain-derived (MBD)-JEV vaccine. The safety profile of JEV-CV was superior to the MBD-JEV vaccine and similar to placebo. The percent of the cohort seroconverting following a single dose of JEV-CV by PRNT with the homologous strain was non-inferior to three doses of the MBD-JEV vaccine (99.1\% vs. 95.1\%) [155]. Additional studies assessing immunization of toddlers and children, co-administration and sequential administration with yellow fever (YF) vaccine (YF-17D strain; Stamaril((R)), Sanofi Pasteur), and administration of a booster doses demonstrated excellent safety profiles and immunogenicity [156].

\section{Murray Valley Encephalitis Virus (MVEV)}

MVEV has caused numerous encephalitis epidemics (Australian X disease) in Australia since the early 1900s. The virus was first isolated in 1951 from the brain of a 19-yearold male who succumbed to infection [3]. Encephalitis outbreaks in 1917, 1918, 1922, and 1925 were initially without an etiologic agent but are now believed to have been MVE [139]. Additional outbreaks occurred in 1956, 1971, 1974, 1978, 1981, and 1984, primarily in the Murray Valley of New South Wales and Victoria [157]. The 1974 outbreak was unique in its geographic expansiveness, infecting people in east central Queensland, Northern Territory, northern and southeastern South Australia, and the Ord River Basin of Western Australia [158]. Between 1978 and 1991 MVE was diagnosed in 26 patients, and 16 were in the Kimberley area of Western Australia [159]. During the 2007-2009 seasons, six human cases of MVEV were reported, at least two fatal, to the National Notifiable Diseases Surveillance System (NNDSS) [160]. Sixteen people are believed to have contracted MVE in 2011 [161]. MVEV is endemic to Papau New Guinea and Irian Jaya [162].

MVEV is a mosquito-borne flavivirus existing in an enzootic cycle involving primarily water birds [161]. Culex annulirostris is believed to be the principal vector, preferring to breed in shallow, warm, fresh water. Although MVE outbreaks occur most often during summer (January to May) and following high rain periods, the ecology remains largely unknown [161, 163]. Viral activity is monitored by trapping and testing mosquitoes or testing sentinel chicken flocks for serologic seroconversion (http://medent.usyd.edu.au/arbovirus/index. html, accessed 28 May 2012). Early indicators of MVEV circulation trigger increased public health vigilance and education regarding personal protective measures.

Complement fixation and neutralizing and crossneutralizing antibody studies demonstrated MVEV was a group B arbovirus in a subgroup containing Japanese encephalitis, West Nile, St. Louis encephalitis, and Kunjin, Usutu, Kokobera, Stratford, and Alfuy viruses [3]. Nucleotide sequencing associates the MVEV most closely with the Japanese encephalitis virus. Phylogenetic studies suggest MVEV emerged in the Malay-Indonesian regions from an African progenitor virus, possibly Usutu. There appears to be persistent homogeneity of MVEV strains from widespread areas throughout Australia different from those circulating in New Guinea. The natural host range of MVEV is broad including humans, chickens, species of water and land birds, horses, dogs, foxes, and opossum. Experimental infection of mice, sheep, chick embryos, and hamsters resulted in death [3]. Culex annulirostris and C. quinquefasciatus and Aedes occidentalis and $A$. vigilax demonstrated competence to infect chicks following ingestion of an infected blood meal, and transovarial transmission following oral infection was achieved with Aedes aegypti [49, 164].

Approximately 1 of every 150-1,000 MVEV infections results in clinical disease. Complete recovery is seen in approximately $40 \%$, long-term neurologic sequelae in $30-50 \%$, and death in 15-30\% [165]. Following an incubation period of 1-4 weeks, patients will experience 2-5 days prodrome of high fever and headache with anorexia, myalgia, nausea, vomiting, diarrhea, rash, or cough [159, 166]. Neurologic features include lethargy, irritability, and confusion with or without seizures. The clinical spectrum of disease can be broad ranging from fever and headache without encephalitis to flaccid paralysis, cranial nerve and brainstem involvement, encephalitis with complete recovery, or death [161]. The disease appears to progress very rapidly in infants [139].

Magnetic resonance imaging (MRI) is the most sensitive and specific imaging study available to support a diagnosis. T2-weighted images demonstrate bilateral hyperintensity of the deep gray matter and may have findings mimicking herpes simplex virus (HSV) encephalitis involving the temporal lobes, red nucleus, and cervical spinal cord.

Laboratory confirmation of infection is achieved through viral isolation, detection of MVEV RNA, a fourfold rise in IgG between acute and convalescent serum samples, or finding IgM in the serum of cerebral spinal fluid (CSF) (http:// www.health.gov.au/internet/main/publishing.nsf/Content/ 
health-arbovirus-mve-guidelines.htm, accessed 29 May 2012). Cross-reactivity among antibody-based tests complicates distinguishing MVEV from other flaviviruses following infection or vaccination. Neutralization assays or an epitope-blocking ELISA may add diagnostic specificity.

There are no licensed vaccines or therapeutics to protect against or treat MVE. Trials of steroids, ribavirin, interferon alpha-2a, and formulations of intravenous immunoglobulin have been evaluated in the context of Japanese encephalitis and West Nile virus infections but with little success [167, 168]. Treatment is supportive and has reduced mortality and morbidity. Passive immunization studies in animals using gamma globulin from MVE and Japanese encephalitis virus survivors demonstrated prophylactic efficacy. The ability of a live chimeric Japanese encephalitis virus vaccine (ChimeriVax-JE) to cross-protect against MVEV in two encephalitis mouse models suggested a single dose elicited a protective and durable immune response [169]. DNA-based and Semliki Forest virus-vectored vaccines using the MVEV prM and $\mathrm{E}$ proteins as immunogens were investigated in a murine model. Both candidates induced durable, MVEspecific neutralizing antibody responses [170].

\section{St. Louis Encephalitis Virus (SLEV)}

The first recognized outbreak of SLE occurred in Paris, Illinois, in 1932 followed the next year by epidemics in St. Louis and Kansas City, Missouri. The virus was first isolated from the brain of a fatal encephalitis case following inoculation in mice and rhesus monkeys [171]. Subsequent SLE outbreaks occurred in the Pacific coast states (1940s), Florida (1959, 1961), Texas, Ohio-Mississippi Valley (1970s), Colorado, California, Florida, Texas, and Arkansas [139, 171-175]. Disease has been reported throughout the majority of the United States, southern Canada, Mexico, and in limited areas of Central and South America [68, 173, 175-209]. There is a diffuse endemicity over vast rural areas, with low rates of seropositives in humans, but with occasional epidemics of hundreds to more than a thousand cases. The monitoring of sentinel flocks of birds for infection has proved useful as an early warning system [174].

The virus is transmitted by a number of culicine mosquitoes, including Culex pipiens and $C$. quinquefasciatus in the East and urban areas of the West, $C$. tarsalis in rural areas of the western states, and $C$. nigripalpus in Florida and southern areas [210-214]. In rural areas of the West and Southwest, it is closely tied to $C$. tarsalis. Depending on the climate of the region, maintenance of the virus can occur by year-round horizontal transmission from bird to mosquito, overwinter survival of infected mosquitoes, or venereal or transovarian infection [215-221].

SLE virus is in the JEV-MVE-West Nile virus complex or subgroup [139, 222, 223]. The virus produces cytopathic effect and plaques in numerous vertebrate cell lines that include primary chick embryo, hamster kidney, BHK-21, Vero, and LLC-MK2. Cell cultures from human, primate, rodent, swine, and avian cell cultures support replication [224]. Natural host range includes wild vertebrate species of birds as well as raccoons, opossums, and bats in North America and birds, rodents, nonhuman primates, and the three-toed sloth in tropical America. SLE varies in virulence for mice [139, 225, 226].

SLE virus has been responsible for thousands of deaths, more than 10,000 severe illnesses, and no fewer than a million mild or subclinical infections [227, 228]. Only 1-2\% of SLE virus infections are symptomatic [210, 229, 230]. The ratio of asymptomatic to symptomatic infection ranges from $800: 1$ in children to $85: 1$ in adults older than 60 years [200, 231]. The infection incubation period ranges between 4 and 21 days. When the disease occurs, it may be classified into three clinical syndromes: constitutional symptoms and headache (febrile headache), aseptic meningitis, and fatal encephalitis [139, 200, 209]. Most cases start with fever, headache, nausea, myalgias, and sometimes respiratory or abdominal symptoms; most recover completely [231]. In those who develop advanced disease, following the acute febrile prodrome, there may be an acute or subacute appearance of meningeal and other neurologic signs and symptoms. Symptoms may include nuchal rigidity, disorientation, unsteady gait, vomiting, and diarrhea. Tremulousness involving the eyelids, tongue, lips, and extremities is observed. Cerebellar and cranial nerve signs are common [231, 232]. Apathy, confusion, and disorientation leading to coma may occur. Nearly one quarter of patients experience urinary symptoms (frequency, urgency, dysuria) [233]. The morality rate is approximately $8 \%$, ranging from approximately $2 \%$ in the young to $22 \%$ in the elderly who have comorbidities [139]. Advanced age is the most significant risk for developing both symptomatic disease and more severe encephalitis after infection [172]. People older than 60 years of age have the highest frequency of encephalitis [139]. Almost $90 \%$ of elderly SLE patients develop encephalitis [230]. Longer-term sequelae such as asthenia, irritability, tremors, sleeplessness, depression, memory loss, and headaches typically last less than 3 years but may last longer. Persistent symptoms include gait and speech disturbances, sensorimotor impairment, psychoneurotic complaints, and tremors [234-236].

Clinical laboratory findings are nondistinct. Peripheral white blood cell count may be high and urine findings may include microscopic hematuria, proteinuria, and pyuria [231]. Inappropriate antidiuretic hormone secretion and hyponatremia may occur in a third of patients. Fewer than $200 / \mathrm{mm}^{3}$ white blood cells are typically seen in the cerebral spinal fluid; polymorphonuclear cells predominate early with an eventual shift toward a lymphocytic pleocytosis. Protein levels may be elevated to 1.5-2.0 times normal. Electroencephalogram shows diffuse slowing and seizure 
activity. Magnetic resonance imaging may show increased signal in the substantia nigra, while radionuclide brain scans and computed tomography have been normal [139, 237].

Diagnosis should be suspected if the patient presents with a compatible clinical syndrome in the summer or early fall, in an area known to have SLE virus circulation, with reports of similar cases with patients at the extremes of age. Although virus isolation has been documented from the liver, spleen, lung, kidney, and brain, isolation is very unusual from serum or CSF [238]. Polymerase chain reaction assays are being developed for diagnosis and surveillance [239-246]. Diagnosis most often is made using serologic assays testing acute and convalescent serum samples or a cerebral spinal fluid sample [21]. IgM antibodies in serum appear within the 4 days after infection, peak at 7-14 days, and then decline and disappear by day 60 but may persist up to a year in a small percentage of patients [139, 231, 247]. A fourfold change in serum antibody titer confirms infection, and presence of $\operatorname{IgM}$ antibody in a single serum is presumptive evidence. Hemagglutinin inhibition detects group-reactive antigens and may be a useful screening test. The presence of complement fixation antibodies in a single serum sample is presumptive evidence of a recent infection, but $20 \%$ of patients with confirmed SLE virus infections do not develop complement fixation antibodies [139]. Detection of IgM antibodies in the cerebral spinal fluid by enzymelinked immunosorbent assay (ELISA) provides a rapid and early diagnosis.

There is no licensed antiviral therapeutic to treat SLE. The current care standard is supportive focusing on controlling seizures, providing respiratory support, reducing cerebral edema, and managing metabolic derangements [231]. There is no licensed vaccine to prevent SLE. Personal protective measures and other vector avoidance practices are encouraged. Control in rural or an urban epidemics has been attempted by emergency application of mosquito control measures. Long-term control for urban and suburban localities depends on good sanitation with respect to drainage and adequate disposal of waste water. In more specific rural areas under irrigation, much can be accomplished through water management and directed application of insecticides to keep mosquito populations low.

\section{Usutu Virus (USUV)}

The USUV is an avian virus discovered in South Africa (1959) in a female mosquito (Culex neavei) [3, 248]. The virus has infectivity for numerous primary and continuous animal species and human cell lines [3]. The life cycle is complex, involving host bird species and Culex mosquitoes as primary vectors and humans, horses, and other mammals as incidental hosts. Geographic range initially includes Senegal, Central African Republic, Nigeria, Uganda, Burkina Faso, Cote d'Ivoire, and Morocco [249]. The virus emerged in Vienna, Austria, in 2001 associated with avian, mainly blackbird, mortality. Infection has recently been noted in a variety of central European birds in Austria, Hungary, Switzerland, United Kingdom, Spain, Germany, and Italy [250, 251]. USUV was initially discovered to be clinically relevant in 1981 when a man in the Central African Republic developed fever and rash following infection. In 2004, a 10-year-old child in Burkina Faso developed fever and jaundice following infection. In 2009, 2 immunosuppressed people (liver transplant, B-cell lymphoma) in Italy developed encephalitis [252, 253]. A recent serosurvey in Northeastern Italy demonstrated 4 of 359 donors had IgG evidence of USUV infection [254].

\section{West Nile Virus (WNV)}

WNV was first isolated in a febrile woman in the West Nile District of Uganda in 1937 [255]. Since its discovery in West Africa, outbreaks of WNV have occurred in many parts of the world, and WNV is now endemic in Africa, Europe, the Middle East, West and Central Asia, Oceania, and North America [256]. In the United States, the westward spread of WNV across the continent from the initial cases in New York over the course of about 5 years was an epidemiologic phenomenon that was closely monitored [257]. WNV now has become the leading cause of neuroinvasive arboviral disease in the United States [258].

Wild birds are the primary vertebrate reservoirs of WNV in endemic regions [259] and WNV has been found to be capable of infecting over 300 different species of birds [260]. In many instances, WNV has spread across continents and regions following bird migration patterns [261]. The virus is transmitted by mosquitoes usually of the Culex spp., though various spp. of Aedes, Anopheles, and Ornithodoros ticks can be infected by WNV [3]. Mammals are less important than birds in maintaining transmission cycles of the virus as viremia is too low in most of the mammal species to reinfect mosquitoes [262].

Nearly all humans are infected with WNV primarily by the bite of infected mosquitoes [257]. However, transmission of WNV to humans has also occurred through transplanted organs, and transfused blood, transplacental transmission [263], and transmission through breast milk may also be likely [264]. Most infections with WNV are asymptomatic. The typical incubation period is 2-14 days, and a self-limited febrile illness without neurologic involvement, known as West Nile fever, may occur in approximately 20-30 \% of infected cases. The symptoms of West Nile fever may include malaise, eye pain, headache, myalgia, gastrointestinal discomfort, and rash. A maculopapular rash occurs in about half of the persons with West Nile fever but is less commonly reported in persons with neuroinvasive disease. About 1 in 150 cases may progress to severe disease and develop encephalitis, men- 
ingitis, or acute flaccid paralysis. Long-term complications (1 year or more after infection) are common in patients recovering from severe WNV infection. Currently, supportive care is the only treatment available. Advanced age is the most important predictor of death [265]. The mortality rate among neuroinvasive disease is approximately $10 \%$, with increased risk for patients with compromised immune systems and advanced age and with underlying conditions such as diabetes mellitus.

Diagnosis of WNV is made primarily by the use of indirect antibody-capture ELISA or PCR. In most cases IgM will be produced within 4-7 days and may persist for more than a year [266]. ELISA for WNV may be performed on serum or CSF. Other serologic tests such as neutralization assays generally are less cross-reactive with other flaviviruses, but are not widely available for clinical diagnosis. Antigen detection assays are also being developed but are not widely used in the clinical setting. PCR is widely available and is very specific and sensitive.

There is no WNV vaccine available for use in humans, but a number of WNV vaccine candidates are in clinical trials. There are three WNV vaccines currently licensed for use in horses; two are killed virus vaccines, and one is a chimeric recombinant canarypox virus vaccine [262].

\section{Yaounde Virus (YAOV)}

The original source of YAOV was a pool of Culex nebulosis female mosquitoes collected in 1968 near Yaounde, Cameroon, Africa [3]. One month later the virus was isolated via intracerebral inoculation in mice. Complement fixation identified the virus as related to Usutu virus. Natural host range includes mosquitoes (Culex spp., Aedes, Eretmapodites), rodent, and bird. Injection in mice produced death. There are no known human cases [3].

\section{Kokobera Virus Complex}

\section{Kokobera Virus (KOKV)}

$\mathrm{KOKV}$ is a mosquito-borne virus that was originally isolated from Culex annulirostris at the Kowanyama (Mitchell River Mission) in northern Queensland in 1960 and named after a local Aboriginal tribe [267]. It is isolated throughout Australia and Papua New Guinea [268]. The reservoir for the virus is thought to be kangaroos, wallabies, and horses. Human infections with KOKV result in an acute polyarticular disease.

\section{Stratford Virus (STRV)}

STRV has a geographic distribution similar to KOKV from Culex species producing a febrile polyarticular illness. Originally classified with KOKV as part of the JEV serocomplex, serologic and sequencing of the virus demonstrated that STRV is closely related to KOKV and its classification into the KOKV complex [3].

\section{New Mapoon Virus}

New Mapoon virus was originally isolated as part of viral isolates obtained from mosquitoes in 1998 on Cape York Peninsula (located Far North Queensland, Australia) and in 2000 on Saibai Island (one of the Torres Strait Islands in Australia, between the Australian mainland and the island of New Guinea) and New Mapoon, Queensland [3]. Viruses were characterized by partial genomic sequencing, monoclonal antibody-binding assays, and polyclonal crossneutralization tests. Two of these isolates were antigenically related to the KOKV complex but distinct. Sequencing demonstrated a distinct novel virus named New Mapoon virus.

\section{Ntaya Virus Complex}

Ilheus Virus (ILHV)

Ilheus virus (ILHV) was isolated from Aedes serratus and Psorophora ferox mosquitoes near Ilheus, Bahia, Brazil, in 1944 [269]. In the original study, Aedes aegypti was demonstrated as a competent vector for this virus. After its discovery, the virus was also isolated from a variety of other mosquito species and birds in Latin America. ILHV was described as producing a febrile illness in humans in Central and South America, but the burden of disease is not well studied. In November 2005, a patient in Bolivia was reported with ILHV who developed fever, malaise, asthenia, conjunctival injection, vesicular rash, facial edema, arthralgia, myalgias, bone pain, abdominal pain, headache, and earache [270].

\section{Ntaya Virus (NTAV)}

Ntaya virus was originally isolated from mosquitoes in Ntaya, Uganda [3]. Isolation has been made from mosquitoes in Uganda, Cameroon, and the Central African Republic and may be endemic in Nigeria, Kenya, and the Zambia [3]. Serologic surveys suggest that this virus may be widespread with antibodies to Ntaya virus in subjects in Tanzania, Egypt, and the Far East. In a study of returning travelers from Africa, three patients tested positive for Ntaya virus. Illness symptoms reported by the travelers included severe malaise, fever, headache, myalgia, and neurologic manifestations of dizziness, numbness, and weakness of the left leg and arm. In one traveler there was severe amblyopia and restriction of the peripheral visual fields.

\section{Other Viruses Within the Ntaya Complex}

Other viruses within this complex are primarily pathogens of poultry causing large epidemics. These include Bagaza virus (BAGV), Israel turkey meningoencephalomyelitis virus (ITV), and Tembusu virus (TMUV). All are spread by a variety of mosquitoes primarily, Culex spp. These viruses have the potential to produce human disease with serologic evidence of human infections though the burden of disease within the human population is not known and thus are 
briefly described. BAGV which is closely related to ITV has been described as producing a febrile illness in humans with one study demonstrating a possible cause of human encephalitis in India. In an outbreak investigation of a severe duck illness in China, a new virus related to TMUV and BAGV was described named BYD virus [271].

\section{Spondweni Virus Complex}

Spondweni Virus (SPOV)

SPOV was first isolated in 1955 from mosquitoes, Taeniorhynchus uniformis collected in Tongaland, South Africa. The name was derived from the location they were collected, the district of Spondweni. A serosurvey of residents in Tongaland demonstrated evidence of infection to SPOV. Human infection was demonstrated in laboratory workers working with the virus characterized as a febrile illness with generalized aches and pains, headache rigors, and vertigo [272]. SPOV has been isolated from humans in Mozambique and Cameroon with serologic evidence of infection in humans in Angolal and Botswana [272]. The virus has been isolated from several mosquito species including Mansonia uniformis, Aedes circumluteolus, M. africana, A. cumminsii, Eretmapodites silvestris, A. fryeri, and A. fowleri [272]. In 1982 a case of acute SPOV infection was reported in a 40-year-old American man, who had worked in Bitou, located in southeastern Upper Volta (Burkina Faso), near the borders of Ghana and Togo [272]. Symptoms included severe headache, dizziness, nausea, muscle aches, eye pain, and sensitivity to light.

\section{Zika Virus (ZIKV)}

ZIKV was originally isolated from a caged febrile rhesus monkey in the Zika Forest, Entebbe, Uganda [273]. Subsequent studies revealed Aedes africanus as the primary vector and a serosurvey demonstrated evidence of human infection [274]. Human infection in a field worker and an experimental infection of a volunteer demonstrated that ZIKV could produce a severe febrile illness associated with headache, myalgias, and prostatitis symptoms [275]. Since its original isolation, ZIKV has been isolated from mosquitoes and a cause of human infections throughout equatorial Africa, Indonesia, Malaysia, and Cambodia. Aedes aegypti was found to be the primary vector in Southeast Asia [276]. In 2007, a large outbreak of ZIKV infection occurred in Yap Island, Micronesia [277]. In total there were 49 confirmed and 59 probable cases of ZIKV illness. Patients developed rash, fever, arthralgia, and conjunctivitis. The authors estimated that $73 \%$ of Yap residents 3 years of age or older had been recently infected with ZIKV. Aedes hensilli was the predominant mosquito species identified. Currently ZIKV is widely distributed outside of Africa with cases or serologic evidence of infection in India, Malaysia, the Philippines, Thailand, Vietnam, and Indonesia. ZIKV was demonstrated to have evolved into an African and
Asian lineage [278]. As noted earlier, ZIKV was documented to have been transmitted sexually from a scientist who was infected in Senegal and, upon returning to the United States, infected his spouse [62].

\section{Yellow Fever Virus Complex}

Banzi Virus (BANV)

BANV was first isolated in 1956 in a 9-year-old boy in Ndumu, South Africa [279]. The clinical manifestations of this virus was a nonspecific febrile illness. There have only been two acute cases of definitively diagnosed BANV infections, but seroprevalence studies across sub-Saharan Africa suggest BANV infections may be largely subclinical and underdiagnosed [3].

\section{Bouboui Virus (BOUV)}

BOUV is a flavivirus that has been isolated in a baboon in Senegal and in mosquitoes in Central Africa and Senegal. While BOUV has never been isolated in humans, seroprevalence studies (employing hemagglutination inhibition assays) involving over 4,000 patients in Central Africa have found 15 patients with serum antibodies to this virus. The clinical manifestations of this disease in humans are not known [3].

\section{Wesselsbron Virus (WESSV)}

WESSV is primarily an arboviral disease of sheep, cattle, and goats [280]. However, it has caused nine cases of human febrile disease in sub-Saharan Africa, sometimes with neurologic complications to include disturbances in speech, hearing, and/or vision [281]. While WESSV is primarily located in Africa, it has been isolated in mosquitoes in Bang Phra, Thailand [3].

\section{Yellow Fever Virus (YFV)}

YFV is the prototype member of the Flaviviridae family of viruses. The origin of YFV is speculated to have been Western Africa, although the disease was first distinguished from other tropical febrile diseases by the Mayans and the Spanish colonists in the Yucatan peninsula in 1648. During the eighteenth and nineteenth centuries, it was one of the great plagues of the world occurring along the eastern US seacoast, in Central America and South America, and in Africa throughout the tropical area [164, 165, 167]. Major epidemics occurred in many seaports of the United States, and the 1905 outbreak in New Orleans was particularly severe. The last US indigenous case occurred in 1911 and the last imported cases in 1924 [13, 214]. It never became established in Europe above the range of the vector, $A$. aegypti mosquitoes. YFV has never been reported from Asia and Australia, despite the endemic presence of $A$. aegypti in tropical Asia [282]. The historical significance of YFV was discussed in a previous section of this chapter. 
The development of the YFV vaccine, Theiler's attenuated live virus vaccine introduced in 1937, represents the first successful vaccine against an arbovirus and forms the basis for the present-day product [283]. YFV is maintained in the environment in two cycles: an urban cycle involving human beings and $A$. aegypti mosquitoes and a sylvatic or jungle YFV cycle involving forest primates, principally monkeys, and forest canopy mosquitoes, with human infections tangential to the transmission cycle [284, 285]. In 1901, eradication efforts directed toward A. aegypti mosquitoes were launched under the direction of Dr. William Gorgas in Havana. These eradication efforts, with concomitant reduction of YFV, were extended throughout Central and South America in the early 1900s. The chain of urban A. aegypti-transmitted YFV was successfully broken by the eradication program. The last endemic focus of $A$. aegypti-transmitted urban YFV was in northeastern Brazil in 1934 [284]. The eradication of the vector, and the concomitant reduction in urban YFV cases in the Americas, historically represents one of the most successful public health campaigns against infectious diseases.

Today, jungle YFV persists in the Western hemisphere and is transmitted chiefly among monkeys, marmosets, and possibly other forest-dwelling animals, commonly causing fatal infections. The vectors are mosquitoes of the forest canopy, chiefly of Haemagogus spp. and, to a lesser extent, $A$. leucocelaenus, Sabethes chloropterus, and possibly A. fulvus in Brazil [285]. For the last few decades in South America, the vast majority of YFV cases were in males over 15 years of age whose occupations increase their exposure to YFVinfected mosquitoes in endemic forest and jungle areas [286, 287]. Up to 500 unvaccinated forest workers were infected in peak years. The majority of cases occur in the first 3 months of the year in South America [287, 288]. A. aegypti has now reinfested most of South and Central America and occupies habitats just adjacent to the areas where endemic YFV transmission occurs. A major threat is that this species could transmit YFV in an urban cycle.

In contrast to the endemic-sylvatic circulation of YFV in the Western hemisphere in the late twentieth century, YFV in Africa periodically explodes out of its sylvatic cycle to infect large numbers during major epidemics. During the decade 1980-1990, YFV reemerged as a major health problem in Africa and, as mentioned above, threatens to reemerge in South America. In Africa, two control strategies have been attempted during the last 40 years. The first was routine immunization programs, and the second was emergency control programs after the start of an outbreak. A routine, mandatory YFV immunization program was begun in the early 1940s in French West Africa, and the recurring pattern of epidemics in West Africa was interrupted in those immunizing countries. This strategy was abandoned in 1960, and the program switched to a post-outbreak, emergency immunization and control strategy. Since then, there has been a series of epidemics of varying severity [285]. The period 1986-1990 represented an extraordinarily active period of YFV. The worldwide total of 17,728 cases and 4,710 deaths (i.e., a case fatality rate of $26.6 \%$ ) represents the greatest amount of YFV activity reported to the WHO for any 5-year period since reporting began in 1948 [286, 287]. However, in Africa, numerous studies have shown that only a small percentage of African YFV cases are reported [287]. Due to the sylvatic cycle of jungle YFV, worldwide eradication is not considered possible. Despite numerous studies, the question of maintenance of YFV in nature remains somewhat obscure. Although a continual vertebrate-vector maintenance cycle is possible in some environments, in other areas overwintering and maintenance probably occur via other mechanisms. The laboratory and field studies that confirmed that YFV virus can be transovarially transmitted in many of its mosquito vectors suggest that this mechanism might play an important role in nature.

Yellow fever patients have a characteristic but nondiagnostic febrile disease with fever, headache, backache, nausea, variable epistaxis, and a lack of correlation between pulse and body temperature [289]. The clinical course is 2-4 days, followed by uneventful recovery or a remission period before development of severe yellow fever. Many tropical diseases, including a variety of arboviral infections, malaria, and relapsing tick fever, may present similar clinical syndromes, making a clinical diagnosis of suspected YFV difficult unless seen during a recognized epidemic. In a serious complication of the disease, the development of icterus occurs following a remission of the general manifestations. It develops as a yellowish tinge of the sclera, a very important diagnostic sign more easily seen in dark-skinned people, and only rarely becomes marked. Hemorrhagic signs and vomiting of blood characterize this more serious form of disease. They are more common preceding death, which usually occurs within 9 days of onset. Mortality rates vary widely and during epidemics reach from 20 to $80 \%$ of the cases. Icteric YFV must be differentiated from infectious and serum hepatitis, leptospirosis, and poisoning.

Because of these uncertain clinical criteria, laboratory diagnostic tests must be used. Isolation and identification of YFV virus in blood samples or necropsy specimens or demonstration of specific antibody titer rises constitutes definitive diagnosis. While the virus generally grows well in standard cell cultures or suckling mice, identification of YFV virus is now usually performed by PCR. Other rapid diagnostic assays have shown promise for demonstration of YFV-specific antigen or IgG and IgM antibodies. Crossreactivity with other flaviviruses has been a historical serologic problem. Demonstration of pathognomonic hepatic lesions in necropsy specimens is used when applicable, but needle biopsies of the liver have proved hazardous and the procedure is not generally recommended. No specific 
therapeutic regimen is available for $\mathrm{YFV}$, and treatment is chiefly supportive. Prevention is based both on protection from exposure and on vaccination. The 17D YFV vaccine was one of the earliest viral vaccines to be developed, and it has proved to be one of the safest and most efficacious live attenuated vaccines [214, 290].

Yellow fever in urban or jungle form is a continuing threat. The two forms are nonetheless the same virus and the same disease, distinguished on epidemiologic grounds. Human beings can be protected by immunization with 17D YFV vaccine (not advised for infants under 1 year of age). A list of the centers in the United States authorized to give the vaccination can be obtained from the Public Health Service (http:// wwwnc.cdc.gov/travel/yellow-fever-vaccination-clinics/ search).

Other Viruses in the Yellow Fever Virus Complex Not Pathogenic to Humans

These viruses include Edge Hill virus (EHV) [3, 267], Jugra virus (JUGV) [3], Saboya virus (SABV) [3], Sepik virus (SEPV) [291], and Uganda $\mathrm{S}$ virus (UGSV) [3]. These known viruses have been shown to cause illness in humans but by potential exposure as indicated by positive antibody titers.

\subsubsection{Viruses with No Known Arthropod Vector}

A number of flaviviruses have no known arthropod vector and no documented naturally occurring infection in humans and includes Entebbe bat virus (ENTV) [3], Yokose virus (YOKV) [3], Apoi virus (APOIV) [3], Cowbone Ridge virus (CRV) [292].

Jutiapa virus (JUTV) [3], Modoc virus (MODV) [293], Sal Vieja virus (SVV) [3], San Perlita virus (SPV) [3], and Carey Island virus (CIV) [3].

\section{Unresolved Problems}

The emergence of WNV in New York and its spread throughout the Americas and the emergence of DENV as a global health problem and recent outbreak in Florida have demonstrated the vulnerability of the United States to emerging viruses. Two studies by the Institute of Medicine dealing with emerging diseases warned that the threat posed by disease-causing microbes may be expected to continue and intensify in coming years [294, 295].

The natural life cycle of many arboviruses is multifaceted and, in addition to the virus, may include one or several reservoir or amplifying hosts and often an arthropod vector. A change affecting the interaction of these fundamental elements might lead to the emergence or reemergence of a viral disease. In some instances, viruses might emerge as the result of selection of new genetic strains and variants with increased infectiousness, virulence, or transmissibility. To control emerging viruses in general, and arthropod-borne viruses in particular, there is a need for expanded (1) basic and applied research that will help formulate coordinated strategies for anticipating, detecting, controlling, and preventing emergence or reemergence of viral diseases and (2) basic and applied research on the virus, the infective process, and the host response to infection, which will be useful in the development of vaccines and antiviral drugs.

Additional unresolved problems are discussed from several points of view, relating to the viruses, the vectors, the vertebrate hosts, and transmission cycles involving virus, vector, and host. The disease in the vertebrate host, which includes the host response to the pathogen, merits independent consideration. Problems relating to the epidemiology of each specific disease require a synthesis of many specific items. Finally, effective control exercised at the level of the virus, the vector, or the vertebrate requires thorough understanding of the epidemiologic background. Specific examples will help to illustrate problems.

\subsection{The Viruses}

Much progress has been made in recent years in cataloging the several hundred described arboviruses and determining the biochemical, growth, and morphological characteristics in intact vertebrates, in invertebrates, and in cell culture systems of vertebrate and invertebrate cells. However, further work is needed to understand the evolution and emergence of epidemiologically relevant strains. In particular, new research is needed on the nucleic acid homology that may exist among the numerous members of a given arbovirus grouping and on the mechanisms of recombination, reassortment, and selection of new virus strains with important virulence properties.

\subsection{The Vectors}

The factors that determine specific virus-vector associations are still being elucidated. The role of the vector in genetic conservation of the arboviruses, as genetic bottlenecks, and virus expansion into other vectors due to mutational events, such as in the case of chikungunya virus, is not well understood. Expanded research is needed before the principles governing virus-vector interactions are carefully delineated.

There is a continuing need for taxonomic refinements with respect to arthropods, such as the need for more information on both Old World and New World mosquitoes of the genera Culex and Aedes. This need is generated by the increasing realization of their involvement with a large number of arboviruses. The same remarks are pertinent for the 
tick vectors. The need is equally great for more information on the biology, feeding preferences, longevity, flight range, and distribution of each arthropod species involved. The genetic constitution of each vector species is basic to an understanding of what constitutes a vector, both physiologically and behaviorally, and will become increasingly important as control of vectors through genetic manipulation is considered [118].

Unfortunately, in 1985, the Asian "tiger" mosquito, A. albopictus, was introduced in old tires imported from Japan to Houston, Texas. It has now spread to infest over 22 states, mostly in the South and Midwest, and has recently become established in several other countries. This mosquito is an aggressive, opportunistic feeder with a wide host range that includes man. It adapts well to forest or urban settings and it can vector many different arboviruses. In some areas, it already has replaced local mosquito species, and there is a concern it will transmit endemic viruses. Because of its potential as a new vector of endemic or emerging arboviruses in the United States and other countries, research on it should receive high priority.

\subsection{The Vertebrate Hosts}

For most of the arboviruses, the primary vertebrate host, i.e., the host that serves as the basic unit for propagation of the virus, is not man. For many of the arboviruses, the vertebrate hosts are not yet determined or are recognized on the most tenuous of evidence. Identification of the host(s) is a primary need. Following this, an emphasis should be placed on elucidating a biological profile of the hosts, including the full range of biological and ecological considerations, as well as the degree of host susceptibility to the virus.

\subsection{Transmission Cycles Involving Virus, Vector, and Vertebrate}

The problem of virus persistence in nature is a particularly baffling one. For example, there are many theories but few facts to explain how a given virus manages to overwinter or survive past a long dry season, when vectors may practically disappear and vertebrate populations decline (or go into hibernation).

Current theories hypothesize that the virus persists in vector populations that overwinter with some members harboring virus or the virus is in vertebrate populations that overwinter and some infected individuals respond to a reactivation stimulus. In other cases, existing data point to an important role for transovarial transmission, permitting passage of virus to generation after generation of a vector without the need for an intercalated vertebrate host.
Several of the tick-transmitted viruses apparently utilize mechanisms of long persistence in ticks plus transovarial transmission of virus to exist in an endemic form in defined geographic areas. An excellent review of this topic is presented by Reeves [139] who discusses the epidemiologic problems of overwintering of arboviruses in northern countries and possible transport via infected vectors on migrating birds, with his discussion extending to the Old World as well as the New World viruses. A related paper by Lord and Calisher [112] discusses the transport of arboviruses in infected migrating birds along the Atlantic coast flyway of the United States. Further research in these areas is vitally needed to determine any point in the natural maintenance of the virus where intervention might lead to control or eradication of the endemic disease.

Studies of transmission cycles are tied closely with simulation of cycles by models with carefully defined parameters. Such models may permit computer manipulation and simulation of field conditions by varying the values applied to defined parameters, following which epidemic curves can be generated. Further work on models is needed, with the hope of eventual prediction of emergence and spread of disease.

\subsection{Disease in the Vertebrate Host}

Studies of the human response to arboviral infections are difficult, since the epidemics that provide numbers of cases for study usually occur unpredictably in time and often far from modern facilities required for detailed clinical investigation. Classically, studies of infection in the vertebrate host (including man) have been part of research programs in the fields of pathology. However, animal models are available for only a limited number of the arboviruses. The development of these models will be crucial for the development modern vaccines and antiviral drugs.

Recognition of disease in the vertebrate host, as well as worldwide surveillance of disease, requires further development of simple diagnostic techniques and standardization of these assays using accepted reference reagents.

\subsection{Control}

Virus vaccines are a highly cost-effective means of disease control; yet for the arboviruses, only an attenuated yellow fever (17D) vaccine is in use on an international scale. The recent WHO recommendation that this vaccine be included in the Expanded Program of Immunization (EPI) in YFV-endemic countries was a major step toward the control of YFV in Africa [200, 201]. The threat of emergence of YFV in South America has prompted some to call for 
consideration of inclusion of YFV vaccine in selected EPI programs in South American countries.

In the case of JEV, an inactivated vaccine has proved highly successful and is in wide-scale use in parts of Asia. An inactivated vaccine for tick-borne encephalitis also has been successfully used for decades in central Europe. However, inactivated vaccines are often costly and need recurring reimmunizations to booster immunity. Advanced testing of the new attenuated JEV vaccine, now in partial use in China, should receive high priority. Research, safety testing, and standardized production studies needed to include such a vaccine in international immunization programs should be strongly supported.

Control at the vector level involves continuing work on methodology for control of arthropods. Development of resistance to various insecticides has impaired many control programs, and recent regulatory actions limiting the use of insecticides have further intensified the need for exploration of alternative methods for vector control.

Limited studies utilizing biological mosquito control (such as Bacillus thuringiensis) to control selected arbovirus vectors have been encouraging and may lead to widespread control strategies. Other approaches that need further research include those that introduce genes into a mosquito population relating to (1) increased insecticide susceptibility, (2) reduced capacity to support virus multiplication and/ or to transmit virus, (3) alternatives in host feeding preferences, (4) reduction in numbers through mutations leading to reduction in reproductive success (sterile males, conditional lethal mutants), and (5) subversions of host feeding habits.

\section{References}

1. Calisher $\mathrm{CH}$, Gould EA. Taxonomy of the virus family Flaviviridae. Adv Virus Res. 2003;59:1-19.

2. Calisher $\mathrm{CH}$. Antigenic classification and taxonomy of flaviviruses (family Flaviviridae) emphasizing a universal system for the taxonomy of viruses causing tick-borne encephalitis. Acta Virol. 1988:32:469-78.

3. International catalog of arboviruses including certain other viruses of vertebrates. Center for Disease Control. 2012. At: http://wwwn. cdc.gov/arbocat/index.asp. Accessed 12 May 2012.

4. Chambers TJ, Hahn CS, Galler R, Rice CM. Flavivirus genome organization, expression, and replication. Ann Rev Microbiol. 1990;44:649-88.

5. Diamond MS. Evasion of innate and adaptive immunity by flaviviruses. Immunol Cell Biol. 2003;81:196-206.

6. Twiddy SS, Pybus OG, Holmes EC. Comparative population dynamics of mosquito-borne flaviviruses. Infect Genet Evol. 2003;3:87-95.

7. Auguste AJ, Pybus OG, Carrington CV. Evolution and dispersal of St. Louis encephalitis virus in the Americas. Infect Genet Evol. 2009;9:709-15.

8. Twiddy SS, Holmes EC, Rambaut A. Inferring the rate and timescale of dengue virus evolution. Mol Biol Evol. 2003;20:122-9.

9. Holmes EC, Twiddy SS. The origin, emergence and evolutionary genetics of dengue virus. Infect Genet Evol. 2003;3:19-28.
10. Staples JE, Monath TP. Yellow fever: 100 years of discovery. JAMA. 2008;300:960-2.

11. Foster KR, Jenkins MF, Toogood AC. The Philadelphia yellow fever epidemic of 1793. Sci Am. 1998;279:88-93.

12. Reed W, Carroll J, Agramonte A. The etiology of yellow fever: an additional note. JAMA. 1901;36:431-40.

13. Downs WG. History of epidemiological aspects of yellow fever Yale J Biol Med. 1982;55:179-85.

14. Sun E, Zhao J, Liu N, et al. Comprehensive mapping of common immunodominant epitopes in the West Nile virus nonstructural protein 1 recognized by avian antibody responses. PLoS One. 2012;7:e31434.

15. Tang XY, Kang K, Li XL, Chen HM, Xu BL. Surveillance on Japanese encephalitis in Henan province, 2006-2010. Zhonghua Liu Xing Bing Xue Za Zhi. 2011;32:1128-30.

16. Hoshino A, Saitoh M, Oka A, et al. Epidemiology of acute encephalopathy in Japan, with emphasis on the association of viruses and syndromes. Brain Dev. 2012;34:337-43.

17. Sakamoto M, Hayashi N, Nakamura Y, Himuro K. Case report; typical MR image findings in Japanese encephalitis; a case report. Nippon Naika Gakkai Zasshi. 2011;100:2256-8.

18. Mansfield KL, Horton DL, Johnson N, et al. Flavivirus-induced antibody cross-reactivity. J Gen Virol. 2011;92:2821-9.

19. Stapleton DH. Lessons of history? Anti-malaria strategies of the International Health Board and the Rockefeller Foundation from the 1920s to the era of DDT. Public Health Rep. 2004;119:206-15.

20. Nájera JA. Malaria control: achievements, problems and strategies. Parassitologia. 2001;43:1-89.

21. Tsai TF. Arboviral infections in the United States. Infect Dis Clin North Am. 1991;5:73-102.

22. Tyler S, Bolling BG, Blair CD, et al. Distribution and phylogenetic comparisons of a novel mosquito flavivirus sequence present in Culex tarsalis Mosquitoes from western Canada with viruses isolated in California and Colorado. Am J Trop Med Hyg. 2011;85:162-8.

23. Le VT, Phan TQ, Do QH, et al. Viral etiology of encephalitis in children in southern Vietnam: results of a one-year prospective descriptive study. PLoS Negl Trop Dis. 2010;4:e854.

24. Jesse M, Mazzucco R, Dieckmann U, Heesterbeek H, Metz JA. Invasion and persistence of infectious agents in fragmented host populations. PLoS One. 2011;6:e24006.

25. Johansson MA, Hombach J, Cummings DA. Models of the impact of dengue vaccines: a review of current research and potential approaches. Vaccine. 2011;29:5860-8.

26. Schlesinger JJ. Flavivirus nonstructural protein NS1: complementary surprises. Proc Natl Acad Sci U S A. 2006;103:18879-80.

27. Alcon-LePoder S, Sivard P, Drouet MT, Talarmin A, Rice C, Flamand M. Secretion of flaviviral non-structural protein NS1: from diagnosis to pathogenesis. Novartis Found Symp. 2006;277:233-47; discussion 47-53.

28. Wang HY, Gao XY, Song LZ. [Isolation and identification of Japanese encephalitis virus firstly in Shandong province]. Zhongguo Yi Miao He Mian Yi. 2009;15:337-40.

29. Eldadah ZA, Asher DM, Godec MS, et al. Detection of flaviviruses by reverse-transcriptase polymerase chain reaction. J Med Virol. 1991;33:260-7.

30. Henchal EA, Polo SL, Vorndam V, Yaemsiri C, Innis BL, Hoke $\mathrm{CH}$. Sensitivity and specificity of a universal primer set for the rapid diagnosis of dengue virus infections by polymerase chain reaction and nucleic acid hybridization. Am J Trop Med Hyg. 1991;45:418-28.

31. Libraty DH, Endy TP, Houng HS, et al. Differing influences of virus burden and immune activation on disease severity in secondary dengue-3 virus infections. J Infect Dis. 2002;185:1213-21.

32. Domingo C, Patel P, Linke S, Achazi K, Niedrig M. Molecular diagnosis of flaviviruses. Future Virol. 2011;6:1059-74. 
33. Gould EA, de Lamballerie X, Zanotto PM, Holmes EC. Evolution, epidemiology, and dispersal of flaviviruses revealed by molecular phylogenies. Adv Virus Res. 2001;57:71-103.

34. Svraka S, Rosario K, Duizer E, van der Avoort H, Breitbart M, Koopmans M. Metagenomic sequencing for virus identification in a public-health setting. J Gen Virol. 2010;91:2846-56.

35. Keeling MJ, Danon L. Mathematical modelling of infectious diseases. Br Med Bull. 2009;92:33-42.

36. Johansson MA, Arana-Vizcarrondo N, Biggerstaff BJ, Gallagher N, Marano N, Staples JE. Assessing the risk of international spread of yellow fever virus: a mathematical analysis of an urban outbreak in Asuncion, 2008. Am J Trop Med Hyg. 2012;86: 349-58.

37. Ciota AT, Kramer LD. Insights into arbovirus evolution and adaptation from experimental studies. Viruses. 2010;2:2594-617.

38. Wittke V, Robb TE, Thu HM, et al. Extinction and rapid emergence of strains of dengue 3 virus during an interepidemic period. Virology. 2002;301:148-56.

39. Weaver SC, Lorenz LH, Scott TW. Pathologic changes in the midgut of Culex tarsalis following infection with Western equine encephalomyelitis virus. Am J Trop Med Hyg. 1992;47: 691-701.

40. Weaver SC, Scott TW, Lorenz LH, Lerdthusnee K, Romoser WS. Togavirus-associated pathologic changes in the midgut of a natural mosquito vector. J Virol. 1988;62:2083-90.

41. Lambrechts L, Scott TW. Mode of transmission and the evolution of arbovirus virulence in mosquito vectors. Proc Biol Sci. 2009;276:1369-78.

42. Powers AM. Genomic evolution and phenotypic distinctions of Chikungunya viruses causing the Indian Ocean outbreak. Exp Biol Med (Maywood). 2011;236:909-14.

43. Moudy RM, Meola MA, Morin LL, Ebel GD, Kramer LD. A newly emergent genotype of West Nile virus is transmitted earlier and more efficiently by Culex mosquitoes. Am J Trop Med Hyg. 2007;77:365-70.

44. Bian G, Xu Y, Lu P, Xie Y, Xi Z. The endosymbiotic bacterium Wolbachia induces resistance to dengue virus in Aedes aegypti. PLoS Pathog. 2010;6:e1000833.

45. Hoffmann AA, Montgomery BL, Popovici J, et al. Successful establishment of Wolbachia in Aedes populations to suppress dengue transmission. Nature. 2011;476:454-7.

46. Petersen LR, Marfin AA. Shifting epidemiology of Flaviviridae. J Travel Med. 2005;12 Suppl 1:S3-11.

47. Endy TP, Anderson KB, Nisalak A, et al. Determinants of inapparent and symptomatic dengue infection in a prospective study of primary school children in Kamphaeng Phet, Thailand. PLoS Negl Trop Dis. 2011;5:e975.

48. Endy TP, Chunsuttiwat S, Nisalak A, et al. Epidemiology of inapparent and symptomatic acute dengue virus infection: a prospective study of primary school children in Kamphaeng Phet, Thailand. Am J Epidemiol. 2002;156:40-51.

49. Mc LD. Transmission of Murray Valley encephalitis virus by mosquitoes. Aust J Exp Biol Med Sci. 1953;31:481-90.

50. Libraty DH, Pichyangkul S, Ajariyakhajorn C, Endy TP, Ennis FA. Human dendritic cells are activated by dengue virus infection: enhancement by gamma interferon and implications for disease pathogenesis. J Virol. 2001;75:3501-8.

51. Weaver SC, Reisen WK. Present and future arboviral threats. Antiviral Res. 2010;85:328-45.

52. Rogers DJ, Packer MJ. Vector-borne diseases, models, and global change. Lancet. 1993;342:1282-4.

53. Schuster G, Ebert EE, Stevenson MA, Corner RJ, Johansen CA. Application of satellite precipitation data to analyse and model arbovirus activity in the tropics. Int J Health Geogr. 2011;10:8.

54. Endy TP, Nisalak A. Japanese encephalitis virus: ecology and epidemiology. Curr Top Microbiol Immunol. 2002;267:11-48.
55. Endy TP, Yoon IK, Mammen MP. Prospective cohort studies of dengue viral transmission and severity of disease. Curr Top Microbiol Immunol. 2010;338:1-13.

56. Nolan MS, Schuermann J, Murray KO. West Nile virus infection among humans, Texas, USA, 2002-2011. Emerg Infect Dis. 2013;19:137-9.

57. Kalayanarooj S, Nimmannitya S. Is dengue severity related to nutritional status? Southeast Asian J Trop Med Public Health. 2005;36:378-84.

58. Stephens HA. HLA and other gene associations with dengue disease severity. Curr Top Microbiol Immunol. 2010;338:99-114.

59. Cisak E, Wojcik-Fatla A, Zajac V, Sroka J, Buczek A, Dutkiewicz J. Prevalence of tick-borne encephalitis virus (TBEV) in samples of raw milk taken randomly from cows, goats and sheep in eastern Poland. Ann Agric Environ Med. 2010;17:283-6.

60. Ruzek D, Yakimenko VV, Karan LS, Tkachev SE. Omsk haemorrhagic fever. Lancet. 2010;376:2104-13.

61. Pealer LN, Marfin AA, Petersen LR, et al. Transmission of West Nile virus through blood transfusion in the United States in 2002. N Engl J Med. 2003;349:1236-45.

62. Foy BD, Kobylinski KC, Chilson Foy JL, et al. Probable nonvector-borne transmission of Zika virus, Colorado, USA. Emerg Infect Dis. 2011;17:880-2.

63. Leitner WW, Costero-Saint Denis A, Wali T. Immunological consequences of arthropod vector-derived salivary factors. Eur J Immunol. 2011;41:3396-400.

64. Styer LM, Lim PY, Louie KL, Albright RG, Kramer LD, Bernard KA. Mosquito saliva causes enhancement of West Nile virus infection in mice. J Virol. 2011;85:1517-27.

65. Brandler S, Brown N, Ermak TH, et al. Replication of chimeric yellow fever virus-dengue serotype 1-4 virus vaccine strains in dendritic and hepatic cells. Am J Trop Med Hyg. 2005;72:74-81.

66. Marovich M, Grouard-Vogel G, Louder M, et al. Human dendritic cells as targets of dengue virus infection. J Investig Dermatol Symp Proc. 2001;6:219-24.

67. Robertson SJ, Mitzel DN, Taylor RT, Best SM, Bloom ME. Tickborne flaviviruses: dissecting host immune responses and virus countermeasures. Immunol Res. 2009;43:172-86.

68. Arboviral surveillance. Update: St. Louis encephalitis in Florida and Texas, 1990. Wkly Epidemiol Rec. 1990;65:351-2.

69. Gaspard P, Mosnier A, Cohen JM, et al. [Respiratory tract infections in institutions for elderly people: the GROG Geronto-Alsace, strategy of surveillance and alert]. Med Mal Infect. 2007;37 Suppl 3:S215-22.

70. St George TD, Doherty RL, Carley JG, et al. The isolation of arboviruses including a new flavivirus and a new Bunyavirus from Ixodes (Ceratixodes) uriae (Ixodoidea: Ixodidae) collected at Macquarie Island, Australia, 1975-1979. Am J Trop Med Hyg. 1985;34:406-12.

71. Viruses, Arthropod-Borne ACo. International catalog of arboviruses including certain other viruses of vertebrates. Fort Collins; 2010. Website: https://wwwn.cdc.gov/arbocat/default.aspx. Atlanta: Arbovirus Catalog, Centers for Disease Control and Prevention. 800-CDC-INFO (800-232-4636).

72. Wang J, Zhang $\mathrm{H}$, Fu S, et al. Isolation of kyasanur forest disease virus from febrile patient, yunnan, china. Emerg Infect Dis. 2009;15:326-8.

73. Gritsun TS, Nuttall PA, Gould EA. Tick-borne flaviviruses. Adv Virus Res. 2003;61:317-71.

74. Mansharamani HJ, Dandawate $\mathrm{CN}$. Experimental vaccine against Kyasanur Forest disease (KFD) virus from tissue culture source. II. Safety testing of the vaccine in cortisone sensitized Swiss albino mice. Indian J Pathol Bacteriol. 1967;10:25-32.

75. Mansharamani HJ, Dandawate CN, Krishnamurthy BG. Experimental vaccine against Kyasanur Forest disease (KFD) virus from tissue culture source. I. Some data on the preparation 
and antigenicity tests of vaccines. Indian $\mathrm{J}$ Pathol Bacteriol. 1967;10:9-24.

76. Pattnaik P. Kyasanur forest disease: an epidemiological view in India. Rev Med Virol. 2006;16:151-65.

77. Dandawate CN, Desai GB, Achar TR, Banerjee K. Field evaluation of formalin inactivated Kyasanur forest disease virus tissue culture vaccine in three districts of Karnataka state. Indian J Med Res. 1994;99:152-8.

78. Gritsun TS, Lashkevich VA, Gould EA. Tick-borne encephalitis. Antiviral Res. 2003;57:129-46.

79. Charrel RN, Zaki AM, Attoui H, et al. Complete coding sequence of the Alkhurma virus, a tick-borne flavivirus causing severe hemorrhagic fever in humans in Saudi Arabia. Biochem Biophys Res Commun. 2001;287:455-61.

80. Charrel RN, Gould EA. Alkhurma hemorrhagic fever in travelers returning from Egypt, 2010. Emerg Infect Dis. 2011;17:1573-4, author reply 4 .

81. Turell MJ, Mores CN, Lee JS, et al. Experimental transmission of Karshi and Langat (tick-borne encephalitis virus complex) viruses by Ornithodoros ticks (Acari: Argasidae). J Med Entomol. 2004;41:973-7.

82. Williams RE, Casals J, Moussa MI, Hoogstraal H. Royal farm virus: a new tickborne group B agent related to the RSSE complex. Am J Trop Med Hyg. 1972;21:582-6.

83. Bancroft WH, Scott RM, Snitbhan R, Weaver Jr RE, Gould DJ. Isolation of Langat virus from Haemaphysalis papuana Thorell in Thailand. Am J Trop Med Hyg. 1976;25:500-4.

84. Webb HE, Wetherley-Mein G, Smith CE, McMahon D. Leukaemia and neoplastic processes treated with Langat and Kyasanur Forest disease viruses: a clinical and laboratory study of 28 patients. $\mathrm{Br}$ Med J. 1966;1:258-66.

85. Webb HE, Connolly JH, Kane FF, O'Reilly KJ, Simpson DI. Laboratory infections with loupingill with associated encephalitis. Lancet. 1968;2:255-8.

86. Davidson MM, Williams H, Macleod JA. Louping ill in man: a forgotten disease. J Infect. 1991;23:241-9.

87. Zeisel MB, Koutsoudakis G, Schnober EK, et al. Scavenger receptor class B type $\mathrm{I}$ is a key host factor for hepatitis $\mathrm{C}$ virus infection required for an entry step closely linked to CD81. Hepatology. 2007;46:1722-31

88. Johnson DK, Staples JE, Sotir MJ, Warshauer DM, Davis JP. Tickborne Powassan virus infections among Wisconsin residents. WMJ. 2010;109:91-7.

89. CDC. Outbreak of Powassan encephalitis - Maine and Vermont, 1999-2001. MMWR Morb Mort Wkly Rep. 2001;50:761-4.

90. Hinten SR, Beckett GA, Gensheimer KF, et al. Increased recognition of Powassan encephalitis in the United States, 1999-2005. Vector Borne Zoonotic Dis. 2008;8:733-40.

91. Mansfield KL, Johnson N, Phipps LP, Stephenson JR, Fooks AR, Solomon T. Tick-borne encephalitis virus - a review of an emerging zoonosis. J Gen Virol. 2009;90:1781-94.

92. Suss J. Tick-borne encephalitis 2010: epidemiology, risk areas, and virus strains in Europe and Asia-an overview. Ticks Tick Borne Dis. 2011;2:2-15.

93. Charrel RN, Attoui H, Butenko AM, et al. Tick-borne virus diseases of human interest in Europe. Clin Microbiol Infect. 2004;10:1040-55.

94. Payan C, Roudot-Thoraval F, Marcellin P, et al. Changing of hepatitis $\mathrm{C}$ virus genotype patterns in France at the beginning of the third millennium: the GEMHEP GenoCII Study. J Viral Hepat. 2005;12:405-13.

95. Varelas-Wesley I, Calisher CH. Antigenic relationships of flaviviruses with undetermined arthropod-borne status. Am J Trop Med Hyg. 1982;31:1273-84.

96. Figueiredo LT. The Brazilian flaviviruses. Microbes Infect. 2000;2:1643-9.
97. Galindo P, Srihongse S, De Rodaniche E, Grayson MA. An ecological survey for arboviruses in Almirante, Panama, 1959-1962. Am J Trop Med Hyg. 1966;15:385-400.

98. Barros VE, Ferreira BR, Livonesi M, Figueiredo LT. Cytokine and nitric oxide production by mouse macrophages infected with Brazilian flaviviruses. Rev Inst Med Trop Sao Paulo. 2009;51:141-7.

99. Sakuma H, Sugai K, Sasaki M. Acute nonparaneoplastic limbic encephalitis in childhood: a case series in Japan. Pediatr Neurol. 2010;43:167-72.

100. Coimbra TL, Nassar ES, Nagamori AH, et al. Iguape: a newly recognized flavivirus from Sao Paulo State, Brazil. Intervirology. 1993;36:144-52.

101. Calisher CH, Gutierrez E, Francy DB, Alava A, Muth DJ, Lazuick JS. Identification of hitherto unrecognized arboviruses from Ecuador: members of serogroups B, C, Bunyamwera, Patois, and Minatitlan. Am J Trop Med Hyg. 1983;32:877-85.

102. Cribier B, Schmitt C, Rey D, Lang JM, Kirn A, Stoll-Keller F. Role of endogenous interferon in hepatitis $\mathrm{C}$ virus (HCV) infection and in coinfection by HIV and HCV. Res Virol. 1996;147:263-6.

103. Batista WC, Tavares Gda S, Vieira DS, Honda ER, Pereira SS, Tada MS. Notification of the first isolation of Cacipacore virus in a human in the State of Rondonia, Brazil. Rev Soc Bras Med Trop. 2011;44:528-30.

104. Butenko AM, Semashko IV, Skvortsova TM, Gromashevskii VL, Kondrashina NG. [Detection of the Koutango virus (Flavivirus, Togaviridae) in Somalia]. Med Parazitol(Mosk). 1986;3:65-8. PMID: 3018465

105. Abushev FA. [Study data on ornithosis infection in the Azerbaijan SSR]. Zh Mikrobiol Epidemiol Immunobiol. 1978;5:83-6.

106. Coz J, Valade M, Cornet M, Robin Y. [Transovarian transmission of a Flavivirus, the Koutango virus, in Aedes aegypti L]. C R Acad Sci Hebd Seances Acad Sci D. 1976;283:109-10.

107. Halstead SB, Thomas SJ. Japanese encephalitis: new options for active immunization. Clin Infect Dis. 2010;50:1155-64.

108. Solomon T, Winter PM. Neurovirulence and host factors in flavivirus encephalitis - evidence from clinical epidemiology. Arch Virol Suppl. 2004;18:161-70.

109. Halstead SB, Jacobson J. Japanese encephalitis. Adv Virus Res. 2003;61:103-38

110. Hammon WM, Sather GE, Mc CH. Serologic survey of Japanese B encephalitis virus infection in birds in Japan. Am J Hyg. 1958;67:118-33.

111. Libraty DH, Nisalak A, Endy TP, Suntayakorn S, Vaughn DW, Innis BL. Clinical and immunological risk factors for severe disease in Japanese encephalitis. Trans R Soc Trop Med Hyg. 2002;96:173-8.

112. Halstead SB, Grosz CR. Subclinical Japanese encephalitis. I. Infection of Americans with limited residence in Korea. Am J Hyg. 1962;75:190-201.

113. Benenson MW, Top Jr FH, Gresso W, Ames CW, Altstatt LB. The virulence to man of Japanese encephalitis virus in Thailand. Am J Trop Med Hyg. 1975;24:974-80.

114. Gajanana A, Thenmozhi V, Samuel PP, Reuben R. A community-based study of subclinical flavivirus infections in children in an area of Tamil Nadu, India, where Japanese encephalitis is endemic. Bull World Health Organ. 1995;73:237-44.

115. Wittesjo B, Eitrem R, Niklasson B, Vene S, Mangiafico JA. Japanese encephalitis after a 10-day holiday in Bali. Lancet. 1995;345:856-7.

116. Caramello P, Canta F, Balbiano R, et al. A case of imported JE acquired during short travel in Vietnam. Are current recommendations about vaccination broader? J Travel Med. 2007;14:346-8.

117. Fischer M, Lindsey N, Staples JE, Hills S. Japanese encephalitis vaccines: recommendations of the Advisory Committee on Immunization Practices (ACIP). MMWR Recomm Rep. 2010;59:1-27. 
118. Hills SL, Griggs AC, Fischer M. Japanese encephalitis in travelers from non-endemic countries, 1973-2008. Am J Trop Med Hyg. 2010;82:930-6.

119. Macdonald WB, Tink AR, Ouvrier RA, et al. Japanese encephalitis after a two-week holiday in Bali. Med J Aust. 1989;150:334-6. 9 .

120. Rose MR, Hughes SM, Gatus BJ. A case of Japanese B encephalitis imported into the United Kingdom. J Infect. 1983;6:261-5.

121. Burdon JT, Stanley PJ, Lloyd G, Jones NC. A case of Japanese encephalitis. J Infect. 1994;28:175-9.

122. Buhl MR, Black FT, Andersen PL, Laursen A. Fatal Japanese encephalitis in a Danish tourist visiting Bali for 12 days. Scand J Infect Dis. 1996;28:189.

123. Buhl MR, Lindquist L. Japanese encephalitis in travelers: review of cases and seasonal risk. J Travel Med. 2009;16:217-9.

124. Saito M, Sunagawa T, Makino Y, et al. Three Japanese encephalitis cases in Okinawa, Japan, 1991. Southeast Asian J Trop Med Public Health. 1999;30:277-9.

125. Vaughn DW, Hoke Jr CH. The epidemiology of Japanese encephalitis: prospects for prevention. Epidemiol Rev. 1992;14:197-221.

126. Markoff L. Points to consider in the development of a surrogate for efficacy of novel Japanese encephalitis virus vaccines Vaccine. 2000;18 Suppl 2:26-32.

127. Kobayashi Y, Hasegawa H, Oyama T, Tamai T, Kusaba T. Antigenic analysis of Japanese encephalitis virus by using monoclonal antibodies. Infect Immun. 1984;44:117-23.

128. Hasegawa H, Yoshida M, Kobayashi Y, Fujita S. Antigenic analysis of Japanese encephalitis viruses in Asia by using monoclonal antibodies. Vaccine. 1995;13:1713-21.

129. Ogata A, Nagashima K, Hall WW, Ichikawa M, Kimura-Kuroda J, Yasui K. Japanese encephalitis virus neurotropism is dependent on the degree of neuronal maturity. J Virol. 1991;65:880-6.

130. Gresser I, Hardy JL, Hu SM, Scherer WF. Factors influencing transmission of Japanese B encephalitis virus by a colonized strain of Culex tritaeniorhynchus Giles, from infected pigs and chicks to susceptible pigs and birds. Am J Trop Med Hyg. 1958;7:365-73.

131. Gresser I, Hardy JL, Scherer WF. The growth curve of Japanese encephalitis virus in the vector mosquito of Japan, Culex tritaeniorhynchus. Jpn J Exp Med. 1958;28:243-8.

132. Gould DJ, Barnett HC, Suyemoto W. Transmission of Japanese encephalitis virus by Culex gelidus Theobald. Trans R Soc Trop Med Hyg. 1962;56:429-35.

133. Okuno T, Mitchell CJ, Chen PS, Hsu S, Ryu E. Experimental transmission of Japanese encephalitis virus by Culex tritaeniorhynchus and C. fuscocephalus. Ann Trop Med Parasitol. 1975;69:203-6.

134. Rosen L, Tesh RB, Lien JC, Cross JH. Transovarial transmission of Japanese encephalitis virus by mosquitoes. Science. 1978;199:909-11

135. Halstead SB, Jacobson J. Japanese encephalitis vaccines. In: Plotkin S, Orenstein W, Offit P, editors. Vaccines. 5th ed. Philadelphia: Saunders/Elsevier; 2008. p. 322.

136. Solomon T, Dung NM, Kneen R, et al. Seizures and raised intracranial pressure in Vietnamese patients with Japanese encephalitis. Brain. 2002;125:1084-93.

137. Sarkari NB, Thacker AK, Barthwal SP, et al. Japanese encephalitis (JE). Part I: clinical profile of 1,282 adult acute cases of four epidemics. J Neurol. 2012;259:47-57.

138. Kumar R, Mathur A, Singh KB, et al. Clinical sequelae of Japanese encephalitis in children. Indian J Med Res. 1993;97:9-13.

139. Burke DS, Monath TP. Flaviviruses. In: Knipe DM, Howley PM, editors. Fields virology. 4th ed. Philadelphia: Lippincott Williams \& Wilkins; 2001. p. 1043-125.

140. Burke DS, Nisalak A, Ussery MA. Antibody capture immunoassay detection of Japanese encephalitis virus immunoglobulin $\mathrm{m}$ and $\mathrm{g}$ antibodies in cerebrospinal fluid. J Clin Microbiol. 1982;16:1034-42.
141. Luo D, Yao R, Song J, Huo H, Wang Z. The effect of DDT spraying and bed nets impregnated with pyrethroid insecticide on the incidence of Japanese encephalitis virus infection. Trans R Soc Trop Med Hyg. 1994;88:629-31.

142. Schioler KL, Samuel M, Wai KL. Vaccines for preventing Japanese encephalitis. Cochrane Database Syst Rev. 2007;3:CD004263.

143. Hoke CH, Nisalak A, Sangawhipa N, et al. Protection against Japanese encephalitis by inactivated vaccines. N Engl J Med. 1988;319:608-14.

144. Beasley DW, Lewthwaite P, Solomon T. Current use and development of vaccines for Japanese encephalitis. Expert Opin Biol Ther. 2008;8:95-106.

145. Andersen MM, Ronne T. Side-effects with Japanese encephalitis vaccine. Lancet. 1991;337:1044.

146. Yu Y. Phenotypic and genotypic characteristics of Japanese encephalitis attenuated live vaccine virus SA14-14-2 and their stabilities. Vaccine. 2010;28:3635-41.

147. Eckels KH, Yu YX, Dubois DR, Marchette NJ, Trent DW, Johnson AJ. Japanese encephalitis virus live-attenuated vaccine, Chinese strain SA14-14-2; adaptation to primary canine kidney cell cultures and preparation of a vaccine for human use. Vaccine. 1988;6:513-8.

148. Kollaritsch H, Paulke-Korinek M, Dubischar-Kastner K. IC51 Japanese encephalitis vaccine. Expert Opin Biol Ther. 2009;9:921-31.

149. Lyons A, Kanesa-thasan N, Kuschner RA, et al. A phase 2 study of a purified, inactivated virus vaccine to prevent Japanese encephalitis. Vaccine. 2007;25:3445-53.

150. Dubischar-Kastner K, Eder S, Buerger V, et al. Long-term immunity and immune response to a booster dose following vaccination with the inactivated Japanese encephalitis vaccine IXIARO, IC51. Vaccine. 2010;28:5197-202.

151. Schuller E, Klade CS, Heinz FX, et al. Effect of pre-existing antitick-borne encephalitis virus immunity on neutralising antibody response to the Vero cell-derived, inactivated Japanese encephalitis virus vaccine candidate IC51. Vaccine. 2008;26:6151-6.

152. Chambers TJ, Nestorowicz A, Mason PW, Rice CM. Yellow fever/ Japanese encephalitis chimeric viruses: construction and biological properties. J Virol. 1999;73:3095-101.

153. Guy B. Immunogenicity of sanofi pasteur tetravalent dengue vaccine. J Clin Virol. 2009;46 Suppl 2:S16-9.

154. Monath TP, McCarthy K, Bedford P, et al. Clinical proof of principle for ChimeriVax: recombinant live, attenuated vaccines against flavivirus infections. Vaccine. 2002;20:1004-18.

155. Torresi J, McCarthy K, Feroldi E, Meric C. Immunogenicity, safety and tolerability in adults of a new single-dose, live-attenuated vaccine against Japanese encephalitis: randomised controlled phase 3 trials. Vaccine. 2010;28:7993-8000.

156. Chokephaibulkit K, Sirivichayakul C, Thisyakorn U, et al. Safety and immunogenicity of a single administration of live-attenuated Japanese encephalitis vaccine in previously primed 2- to 5-yearolds and naive 12- to 24-month-olds: multicenter randomized controlled trial. Pediatr Infect Dis J. 2010;29:1111-7.

157. Marshall ID. Murray Valley and Kunjin encephalitis. In: The arboviruses: ecology and epidemiology. Boca Raton: CRC Press; 1988. p. 151-90.

158. Smith DW, Broom AK, Keil A, Mackenzie JS. Murray Valley encephalitis acquired in Western Australia. Med J Aust. 1991;154:845-6.

159. Mackenzie JS, Smith DW, Broom AK, Bucens MR. Australian encephalitis in Western Australia, 1978-1991. Med J Aust. 1993;158:591-5.

160. Fitzsimmons GJ, Wright P, Johansen CA, Whelan PI. Arboviral diseases and malaria in Australia, 2008-09: annual report of the National Arbovirus and Malaria Advisory Committee. Commun Dis Intell. 2010;34:225-40. 
161. Knox J, Cowan RU, Doyle JS, et al. Murray Valley encephalitis: a review of clinical features, diagnosis and treatment. Med J Aust. 2012;196:322-6.

162. French EL, Anderson SG, Price AV, Rhodes FA. Murray Valley encephalitis in New Guinea. I. Isolation of Murray Valley encephalitis virus from the brain of a fatal case of encephalitis occurring in a Papuan native. Am J Trop Med Hyg. 1957;6:827-34.

163. Carver S, Bestall A, Jardine A, Ostfeld RS. Influence of hosts on the ecology of arboviral transmission: potential mechanisms influencing dengue, Murray Valley encephalitis, and Ross River virus in Australia. Vector Borne Zoonotic Dis. 2009;9:51-64.

164. Kay BH, Carley JG. Transovarial transmission of Murray Valley encephalitis virus by Aedes aegypti (L). Aust J Exp Biol Med Sci. 1980;58:501-4.

165. Bennett NM. Murray Valley encephalitis, 1974: clinical features. Med J Aust. 1976;2:446-50.

166. Robertson EG, Mc LH. Murray Valley encephalitis; clinical aspects. Med J Aust. 1952;1:103-7.

167. Broom AK, Wallace MJ, Mackenzie JS, Smith DW, Hall RA. Immunisation with gamma globulin to Murray Valley encephalitis virus and with an inactivated Japanese encephalitis virus vaccine as prophylaxis against Australian encephalitis: evaluation in a mouse model. J Med Virol. 2000;61:259-65.

168. Ben-Nathan D, Gershoni-Yahalom O, Samina I, et al. Using high titer West Nile intravenous immunoglobulin from selected Israeli donors for treatment of West Nile virus infection. BMC Infect Dis. 2009;9:18.

169. Lobigs M, Larena M, Alsharifi M, Lee E, Pavy M. Live chimeric and inactivated Japanese encephalitis virus vaccines differ in their cross-protective values against Murray Valley encephalitis virus. J Virol. 2009;83:2436-45.

170. Colombage G, Hall R, Pavy M, Lobigs M. DNA-based and alphavirus-vectored immunisation with prM and $\mathrm{E}$ proteins elicits long-lived and protective immunity against the flavivirus, Murray Valley encephalitis virus. Virology. 1998;250:151-63.

171. Burke DS, Monath TP. Fields virology. In: Knipe DM, Howley PM, editors. Fields virology. Philadelphia: Lippincott Williams \& Wilkins; 2001. p. 1043-125.

172. Marfin AA, Bleed DM, Lofgren JP, et al. Epidemiologic aspects of a St. Louis encephalitis epidemic in Jefferson County Arkansas, 1991. Am J Trop Med Hyg. 1993;49:30-7.

173. Tsai TF, Canfield MA, Reed CM, et al. Epidemiological aspects of a St. Louis encephalitis outbreak in Harris County, Texas, 1986. J Infect Dis. 1988;157:351-6.

174. Reisen WK, Meyer RP, Milby MM, et al. Ecological observations on the 1989 outbreak of St. Louis encephalitis virus in the southern San Joaquin Valley of California. J Med Entomol. 1992;29:472-82.

175. Tsai TF, Cobb WB, Bolin RA, et al. Epidemiologic aspects of a St. Louis encephalitis outbreak in Mesa County, Colorado. Am J Epidemiol. 1987;126:460-73.

176. Spinsanti LI, Diaz LA, Glatstein N, et al. Human outbreak of St. Louis encephalitis detected in Argentina, 2005. J Clin Virol. 2008;42:27-33.

177. Reimann CA, Hayes EB, DiGuiseppi C, et al. Epidemiology of neuroinvasive arboviral disease in the United States, 1999-2007. Am J Trop Med Hyg. 2008;79:974-9.

178. Shaman J, Day JF, Stieglitz M. The spatial-temporal distribution of drought, wetting, and human cases of St. Louis encephalitis in southcentral Florida. Am J Trop Med Hyg. 2004;71:251-61.

179. Jones SC, Morris J, Hill G, Alderman M, Ratard RC. St. Louis encephalitis outbreak in Louisiana in 2001. J La State Med Soc. 2002;154:303-6.

180. Reisen WK. Epidemiology of St. Louis encephalitis virus. Adv Virus Res. 2003;61:139-83.

181. Bleed DM, Marfin AA, Karabatsos N, et al. St. Louis encephalitis in Arkansas. J Ark Med Soc. 1992;89:127-30.
182. Centers for Disease C. St. Louis encephalitis outbreak - Arkansas, 1991. MMWR Morb Mort Wkly Rep. 1991;40:605-7.

183. Centers for Disease C. Update: St. Louis encephalitis - Florida and Texas, 1990. MMWR Morb Mort Wkly Rep. 1990;39:756-9.

184. Arboviral surveillance. Update: St. Louis encephalitis in Florida and Texas, United States, 1990. Can Dis Wkly Rep. 1990;16:243-4.

185. Centers for Disease C. St. Louis encephalitis - Baytown and Houston, Texas. MMWR Morb Mort Wkly Rep. 1986;35:693-5.

186. Centers for Disease C. St. Louis encephalitis - California. MMWR Morb Mort Wkly Rep. 1984;33:649-51.

187. Nelson DB, Kappus KD, Janowski HT, Buff E, Wellings FM, Schneider NJ. St. Louis encephalitis - Florida 1977. Patterns of a widespread outbreak. Am J Trop Med Hyg. 1983;32:412-6.

188. Paulson GW, Brinker KR. St. Louis encephalitis epidemic in Ohio in 1975. Ohio State Med J. 1978;74:491-3.

189. Maetz HM, Pate P, Sellers C, Bailey WC, Holmes R, Hardy Jr GE. Epidemiology and control of St. Louis encephalitis in Birmingham, Alabama, 1975. Am J Public Health. 1978;68:588-90.

190. Levy JS, Carver HD, Moseley IK, Calisher CH, Francy DB, Monath TP. St. Louis encephalitis in Memphis-Shelby County, Tennessee, 1975: epidemiologic aspects of human cases. South Med J. 1978;71:633-7.

191. Creech WB. St. Louis encephalitis in the United States, 1975. J Infect Dis. 1977;135:1014-6.

192. Powell KE, Blakey DL. St. Louis encephalitis: clinical and epidemiologic aspects, Mississippi, 1974. South Med J. 1976;69:1121-5.

193. Bruetman ME, Deam M, Reyes MG, Harrison W. St. Louis Encephalitis (SLE) in a middle-class population in Northern Illinois. Trans Am Neurol Assoc. 1976;101:223-4.

194. Williams KH, Hollinger FB, Metzger WR, Hopkins CC, Chamberlain RW. The epidemiology of St. Louis encephalitis in Corpus Christi, Texas, 1966. Am J Epidemiol. 1975;102:16-24.

195. Hopkins CC, Hollinger FB, Johnson RF, Dewlett HJ, Newhouse VF, Chamberlain RW. The epidemiology of St. Louis encephalitis in Dallas, Texas, 1966. Am J Epidemiol. 1975;102:1-15.

196. Gonzalez Cortes A, Zarate Aquino ML, Guzman Bahena J, Miro Abella J, Cano Avila G, Aguilera AM. St. Louis encephalomyelitis in Hermosillo, Sonora, Mexico. Bull Pan Am Health Organ. 1975;9:306-16.

197. Rubin RH, Glick TH, Rose NJ. St. Louis encephalitis in Saline County, Illinois, 1968. J Infect Dis. 1970;122:347-53.

198. Kriel RL, Poland JD, Jonsson V, Chin TD. St. Louis encephalitis in St. Louis County, Missouri, during 1966. Am J Trop Med Hyg. 1969;18:460-5.

199. Goldfield M, Altman R, Welsh JN, et al. The 1964 outbreak of St. Louis encephalitis in the Delaware Valley. 2. Laboratory studies of cases and serologic diagnostic procedures. Am J Epidemiol. $1968 ; 87: 470-83$

200. Luby JP, Miller G, Gardner P, Pigford CA, Henderson BE, Eddins D. The epidemiology of St. Louis encephalitis in Houston, Texas, 1964. Am J Epidemiol. 1967;86:584-97.

201. Galindo P, Peralta PH, Mackenzie RB, Beye HK. St. Louis encephalitis in panama: a review and a progress report. Am J Trop Med Hyg. 1964;13:455.

202. Sullivan TD, Grimes JE, Irons JV, Peavy JE. Lower Rio Grande valley outbreak of St. Louis encephalitis. Tex Rep Biol Med. 1959;17:439-43.

203. Jahraus RC. St. Louis encephalitis in South Dakota; a case report. South Dakota J Med Pharm. 1959;12:177-8. passim.

204. Giddings LE, Smith LW, Beaver ME, Sooter CA. St. Louis encephalitis outbreak during 1956 in Grand Junction, Colo. Public Health Rep. 1959;74:372-5.

205. Galindo P, de Rodaniche E, Johnson CM. St. Louis encephalitis in Panama. I. Isolation of the virus from forest mosquitoes and human blood. Am J Trop Med Hyg. 1959;8:557-60. 
206. Ranzenhofer ER, Alexander ER, Beadle LD, Bernstein A, Pickard RC. St. Louis encephalitis in Calvert City, Kentucky, 1955; an epidemiologic study. Am J Hyg. 1957;65:147-61.

207. An outbreak of St. Louis encephalitis in the Lower Rio Grande Valley of Texas in 1954. Public Health Rep. 1957;72:510-1.

208. Hollister Jr AC, Longshore Jr WA, Dean BH, Stevens IM. The 1952 outbreak of encephalitis in California; epidemiologic aspects. Calif Med. 1953;79:84-90.

209. Monath TP, Tsai TF. St. Louis encephalitis: lessons from the last decade. Am J Trop Med Hyg. 1987;37:40S-59.

210. Bell RL, Christensen B, Holguin A, Smith O. St. Louis encephalitis: a comparison of two epidemics in Harris county, Texas. Am J Public Health. 1981;71:168-70.

211. Centers for Disease Control (CDC). Arboviral infections of the central nervous system - United States, 1985. MMWR Morb Mortal Wkly Rep. 1986;35:341-4, 9-50.

212. Centers for Disease Control (CDC). St. Louis encephalitis California. MMWR Morb Mortal Wkly Rep. 1984;33:649-51.

213. Centers for Disease Control (CDC). Arboviral infections of the central nervous system - United States, 1984. MMWR Morb Mortal Wkly Rep. 1985;34:283-6. 91-4.

214. Theiler M, Downs WG. The arthropod-borne viruses of vertebrates. New Haven: Yale University Press; 1973.

215. Reisen WK, Milby MM, Presser SB, Hardy JL. Ecology of mosquitoes and St. Louis encephalitis virus in the Los Angeles Basin of California, 1987-1990. J Med Entomol. 1992;29:582-98.

216. Bailey CL, Faran ME, Gargan 2nd TP, Hayes DE. Winter survival of blood-fed and nonblood-fed Culex pipiens L. Am J Trop Med Hyg. 1982;31:1054-61.

217. Francy DB, Rush WA, Montoya M, Inglish DS, Bolin RA. Transovarial transmission of St. Louis encephalitis virus by Culex pipiens complex mosquitoes. Am J Trop Med Hyg. 1981;30:699-705.

218. Shroyer DA. Venereal transmission of St. Louis encephalitis virus by Culex quinquefasciatus males (Diptera: Culicidae). J Med Entomol. 1990;27:334-7.

219. Flores FS, Diaz LA, Batallan GP, Almiron WR, Contigiani MS Vertical transmission of St. Louis encephalitis virus in Culex quinquefasciatus (Diptera: Culicidae) in Cordoba, Argentina. Vector Borne Zoonotic Dis. 2010;10:999-1002.

220. Day JF, Curtis GA. Blood feeding and oviposition by Culex nigripalpus (Diptera: Culicidae) before, during, and after a widespread St. Louis encephalitis virus epidemic in Florida. J Med Entomol. 1999;36:176-81.

221. Day JF, Curtis GA, Edman JD. Rainfall-directed oviposition behavior of Culex nigripalpus (Diptera: Culicidae) and its influence on St. Louis encephalitis virus transmission in Indian River County, Florida. J Med Entomol. 1990;27:43-50.

222. De Madrid AT, Porterfield JS. The flaviviruses (group B arboviruses): a cross-neutralization study. J Gen Virol. 1974;23:91-6.

223. Pond WL, Russ SB, Rogers NG, Smadel JE. Murray Valley encephalitis virus: its serological relationship to the Japanese-West Nile-St. Louis encephalitis group of viruses. J Immunol. 1955;75:78-84.

224. Karabatsos N. St. Louis encephalitis. In: Monath TP, editor. St Louis encephalitis. Washington, D.C.: American Public Health Association; 1980. p. 115-24.

225. Monath TP, Cropp CB, Bowen GS, Kemp GE, Mitchell CJ, Gardner JJ. Variation in virulence for mice and rhesus monkeys among St. Louis encephalitis virus strains of different origin. Am J Trop Med Hyg. 1980;29:948-62.

226. Bowen GS, Monath TP, Kemp GE, Kerschner JH, Kirk LJ. Geographic variation among St. Louis encephalitis virus strains in the viremic responses of avian hosts. Am J Trop Med Hyg. 1980;29:1411-9.

227. Monath TP. Epidemiology. In: Monath TP, editor. St Louis encephalitis. Washington, D.C.: American Public Health Association; 1980. p. 239-312.

228. Chamberlain RW. History of St. Louis encephalitis. In: Monath TP, editor. St. Louis encephalitis. Washington, D.C.: American Public Health Association; 1980. p. 3-61.
229. Brody JA, Burns KF, Browning G, Schattner JD. Apparent and inapparent attack rates for St. Louis encephalitis in a selected population. N Engl J Med. 1959;261:644-6.

230. Calisher $\mathrm{CH}$. Medically important arboviruses of the United States and Canada. Clin Microbiol Rev. 1994;7:89-116.

231. Vaughn DW, Barrett A, Solomon T. Flaviviruses (Yellow Fever, Dengue, Dengue Hemorrhagic Fever, Japanese Encephalitis, West Nile Encephalitis, St. Louis Encephalitis, Tick-Borne Encephalitis). In: Mandell GL, Bennett JE, Dolin R, editors. Mandell: Mandell, Douglas, and Bennett's principles and practice of infectious diseases. 7th ed. Philadelphia: Churchill Livingstone Elsevier; 2010. p. 2133-56.

232. Wasay M, Diaz-Arrastia R, Suss RA, et al. St Louis encephalitis: a review of 11 cases in a 1995 Dallas, Tex, epidemic. Arch Neurol. 2000;57:114-8.

233. Quick DT, Thompson JM, Bond JO. The 1962 epidemic of St. Louis encephalitis in Florida. IV. Clinical features of cases occurring in the Tampa Bay area. Am J Epidemiol. 1965;81:415-27.

234. Finley KH, Riggs N. Convalescence and sequelae. In: Monath TP, editor. St. Louis encephalitis. Washington, D.C.: American Public Health Association; 1980. p. 535-50.

235. Azar GJ, Chappell GL, Lawton AH, Bond JO. Follow-up studies of St. Louis encephalitis in Florida: sensorimotor findings. Am J Public Health Nations Health. 1966;56:1074-81.

236. Palmer RJ, Finley KH. Sequelae of encephalitis; report of a study after the California epidemic. Calif Med. 1956;84:98-100.

237. Cerna F, Mehrad B, Luby JP, Burns D, Fleckenstein JL. St. Louis encephalitis and the substantia nigra: MR imaging evaluation. AJNR Am J Neuroradiol. 1999;20:1281-3.

238. Calisher CH, Poland JD. Laboratory diagnosis. In: Monath TP, editor. St. Louis encephalitis. Washington, D.C.: American Public Health Association; 1980. p. 571-601.

239. Nawrocki SJ, Randle YH, Vodkin MH, Siegel JP, Novak RJ. Evaluation of a reverse transcriptase-polymerase chain reaction assay for detecting St. Louis encephalitis virus using fieldcollected mosquitoes (Diptera: Culicidae). J Med Entomol. 1996;33:123-7.

240. Dyer J, Chisenhall DM, Mores CN. A multiplexed TaqMan assay for the detection of arthropod-borne flaviviruses. J Virol Methods. 2007;145:9-13.

241. Chao DY, Davis BS, Chang GJ. Development of multiplex realtime reverse transcriptase PCR assays for detecting eight medically important flaviviruses in mosquitoes. J Clin Microbiol. 2007;45:584-9.

242. Ayers M, Adachi D, Johnson G, Andonova M, Drebot M, Tellier R. A single tube RT-PCR assay for the detection of mosquitoborne flaviviruses. J Virol Methods. 2006;135:235-9.

243. Howe DK, Vodkin MH, Novak RJ, Shope RE, McLaughlin GL. Use of the polymerase chain reaction for the sensitive detection of St. Louis encephalitis viral RNA. J Virol Methods. 1992;36:101-10.

244. Howe DK, Vodkin MH, Novak RJ, Mitchell CJ, McLaughlin GL. Detection of St. Louis encephalitis virus in mosquitoes by use of the polymerase chain reaction. J Am Mosq Control Assoc. 1992;8:333-5.

245. Re V, Spinsanti L, Farias A, et al. Reliable detection of St. Louis encephalitis virus by RT-nested PCR. Enferm Infecc Microbiol Clin. 2008;26:10-5.

246. Hull R, Nattanmai S, Kramer LD, Bernard KA, Tavakoli NP. A duplex real-time reverse transcriptase polymerase chain reaction assay for the detection of St. Louis encephalitis and eastern equine encephalitis viruses. Diagn Microbiol Infect Dis. 2008;62:272-9.

247. Monath TP, Nystrom RR, Bailey RE, Calisher CH, Muth DJ. Immunoglobulin $\mathrm{M}$ antibody capture enzyme-linked immunosorbent assay for diagnosis of St. Louis encephalitis. J Clin Microbiol. 1984;20:784-90.

248. Bago Z, Bauder B, Kolodziejek J, Nowotny N, Weissenbock H. Tickborne encephalitis in a mouflon (Ovis ammon musimon). Vet Rec. 2002;150:218-20. 
249. Nikolay B, Diallo M, Boye CS, Sall AA. Usutu virus in Africa. Vector Borne Zoonotic Dis. 2011;11:1417-23.

250. Jost H, Bialonski A, Maus D, et al. Isolation of usutu virus in Germany. Am J Trop Med Hyg. 2011;85:551-3.

251. Bakonyi T, Erdelyi K, Ursu K, et al. Emergence of Usutu virus in Hungary. J Clin Microbiol. 2007;45:3870-4.

252. Pecorari M, Longo G, Gennari W, et al. First human case of Usutu virus neuroinvasive infection, Italy, August-September 2009. Euro Surveill. 2009;14.

253. Cavrini F, Gaibani P, Longo G, et al. Usutu virus infection in a patient who underwent orthotropic liver transplantation, Italy, August-September 2009. Euro Surveill. 2009;14.

254. Gaibani P, Pierro A, Alicino R, et al. Detection of Usutu-virusspecific IgG in blood donors from Northern Italy. Vector Borne Zoonotic Dis. 2012;12:431-3.

255. Smithburn KC, Hughes TP, Burke AW, Paul JH. A neurotropic virus isolated from the blood of a native of Uganda. Am J Trop Med Hyg. 1940;s1-20:471-92.

256. Komar N. West Nile viral encephalitis. Rev Sci Tech 2000;19:166-76

257. Hayes EB, Komar N, Nasci RS, Montgomery SP, O'Leary DR, Campbell GL. Epidemiology and transmission dynamics of West Nile virus disease. Emerg Infect Dis. 2005;11:1167-73.

258. (CDC) CfDCaP. West Nile virus disease and other arboviral diseases - United States, 2010. MMWR Morb Mortal Wkly Rep 2011;60(3):1009-13.

259. Work TH, Hurlbut HS, Taylor RM. Indigenous wild birds of the Nile Delta as potential West Nile virus circulating reservoirs. Am J Trop Med Hyg. 1955;4:872-88.

260. CDC: West Nile Virus - vertebrate ecology > bird species. 2012 Accessed at: http://www.cdc.gov/ncidod/dvbid/westnile/birdspecies.htm.

261. Mackenzie JS, Gubler DJ, Petersen LR. Emerging flaviviruses: the spread and resurgence of Japanese encephalitis, West Nile and dengue viruses. Nat Med. 2004;10:S98-109.

262. De Filette M, Ulbert S, Diamond M, Sanders NN. Recent progress in West Nile virus diagnosis and vaccination. Vet Res. 2012;43:16

263. (CDC) CfDCaP. Intrauterine West Nile virus infection - New York, 2002. MMWR Morb Mortal Wkly Rep. 2002;51:1135-6.

264. (CDC) CfDCaP. Possible West Nile virus transmission to an infant through breast-feeding - Michigan, 2002. MMWR Morb Mortal Wkly Rep. 2002;51:877-8.

265. Petersen LR, Marfin AA. West Nile virus: a primer for the clinician. Ann Intern Med. 2002;137:173-9.

266. Roehrig JT, Nash D, Maldin B, et al. Persistence of virus-reactive serum immunoglobulin $\mathrm{m}$ antibody in confirmed West Nile virus encephalitis cases. Emerg Infect Dis. 2003;9:376-9.

267. Doherty RL, Carley JG, Mackerras MJ, Marks EN. Studies of arthropod-borne virus infections in Queensland. III. Isolation and characterization of virus strains from wild-caught mosquitoes in North Queensland. Aust J Exp Biol Med Sci. 1963;41:17-39.

268. Mackenzie JS, Lindsay MD, Coelen RJ, Broom AK, Hall RA, Smith DW. Arboviruses causing human disease in the Australasian zoogeographic region. Arch Virol. 1994;136:447-67.

269. Purse BV, Mellor PS, Rogers DJ, Samuel AR, Mertens PP, Baylis $\mathrm{M}$. Climate change and the recent emergence of bluetongue in Europe. Nat Rev Microbiol. 2005;3:171-81.

270. Hay SI, Shanks GD, Stern DI, Snow RW, Randolph SE, Rogers DJ. Climate variability and malaria epidemics in the highlands of East Africa. Trends Parasitol. 2005;21:52-3.

271. Su J, Li S, Hu X, et al. Duck egg-drop syndrome caused by BYD virus, a new Tembusu-related flavivirus. PLoS One. 2011;6:e18106.

272. Braverman Y, Baylis M, Tatem AJ, Rogers DJ, Mellor PS, Purse BV. What factors determine when epidemics occur in the Mediterranean? Prediction of disease risk through time by climate-driven models of the temporal distribution of outbreaks in Israel. Vet Ital. 2004;40:235-42.

273. Dick GW, Kitchen SF, Haddow AJ. Zika virus. I. Isolations and serological specificity. Trans $\mathrm{R}$ Soc Trop Med Hyg. 1952;46:509-20.

274. Dick GW. Zika virus. II. Pathogenicity and physical properties. Trans R Soc Trop Med Hyg. 1952;46:521-34.

275. Filipe AR, Martins CM, Rocha H. Laboratory infection with Zika virus after vaccination against yellow fever. Arch Gesamte Virusforsch. 1973;43:315-9.

276. Marchette NJ, Garcia R, Rudnick A. Isolation of Zika virus from Aedes aegypti mosquitoes in Malaysia. Am J Trop Med Hyg. 1969;18:411-5.

277. Duffy MR, Chen TH, Hancock WT, et al. Zika virus outbreak on Yap Island, Federated States of Micronesia. N Engl J Med. 2009;360:2536-43.

278. Randolph SE, Rogers DJ. A generic population model for the African tick Rhipicephalus appendiculatus. Parasitology. 1997;115(Pt 3):265-79.

279. Smithburn KC, Kokernot RH, Heymann CS, Weinbren MP, Zentkowsky D. Neutralizing antibodies for certain viruses in the sera of human beings residing in Northern Natal. S Afr Med J. 1959;33:555-61.

280. Blackburn NK, Swanepoel R. An investigation of flavivirus infections of cattle in Zimbabwe Rhodesia with particular reference to Wesselsbron virus. J Hyg (Lond). 1980;85:1-33.

281. Heymann CS, Kokernot RH, De Meillon B. Wesselsbron virus infections in man. S Afr Med J. 1958;32:543-5.

282. Sawyer WA. Virus diseases and the public health. Am J Public Health Nations Health. 1937;27:1129-34.

283. Norrby E. Yellow fever and Max Theiler: the only Nobel Prize for a virus vaccine. The Rockefeller University Press, J Exp Med. 2007;204(12):2779-84. doi: 10.1084/jem.20072290.

284. WHO Expert Committee on Yellow Fever. Third report. World Health Organ Tech Rep Ser. 1971;479:1-56.

285. WHO. Prevention and control of yellow fever in Africa. Geneva: WHO; 1986

286. WHO. Yellow Fever in 1988. Wkly Epidemiol Rec. 1990;65:8.

287. WHO. Yellow Fever in 1989 and 1990. Wkly Epidemiol Rec. 1992;67:8.

288. Update on yellow fever in the Americas. Epidemiol Bull 2000;21(2):13

289. WHO Expert Committee on Yellow Fever. Third report. World Health Organ Tech Rep Ser. 1971;479:1-56.

290. Theiler M, Smith HH. The use of yellow fever virus modified by in vitro cultivation for human immunization. J Exp Med. 1937;65:787-800. Rev Med Virol. 2000;10:6-16; discussion 3-5.

291. Woodroofe GM, Marshall ID. Arboviruses from the Sepik district of New Guinea. In: John Curtin School of Medical Research Annual Report. Canberra: Australian National University; 1971. p. $90-1$.

292. Calisher CH, Davie J, Coleman PH, Lord RD, Work TH. Cowbone Ridge virus, a new group B arbovirus from South Florida. Am J Epidemiol. 1969;89:211-6.

293. Johnson HN. Ecological implications of antigenically related mammalian viruses for which arthropod vectors are unknown and avian associated soft tick viruses. Jpn J Med Sci Biol. 1967;20(Suppl):160-6.

294. Lederberg J, Shope RE, Oaks SC, editors. Emerging infections: microbial threats to the health in the United States. Washington, D.C.: National Academy Press; 1992.

295. Anonymous. Microbial threats to health: emergence, detection, and response. Washington, D.C.: Institute of Medicine; 2003.

296. Gould EA, Solomon T. Pathogenic Flaviviruses. Lancet 2008;371: 500-09. 